\title{
Capital Malleability and the Macroeconomic Costs of Climate Policy
}

\author{
Elisa Lanzi* \\ School of Advanced Studies in Venice (SSAV) and Fondazione ENI Enrico Mattei (FEEM) \\ Ian Sue Wing \\ Dept. of Geography \& Environment, Boston University \\ and Joint Program on the Science \& Policy of Global Change, MIT
}

\begin{abstract}
This paper argues for introducing the role of capital malleability into the analysis of environmental policies. The issue is explored by means of a theoretical model, a numerical analysis and a computable general equilibrium (CGE) model. Considering the three approaches together is fundamental in obtaining theory-compatible policy-relevant results. The model outcomes reveal differences between results under separate assumptions regarding the malleability of capital. When capital is imperfectly malleable a carbon policy is less effective than under the assumption of perfect malleability of capital. Therefore, it is important that, especially for the analysis of short-term environmental regulations, the issue of capital malleability is taken into consideration.
\end{abstract}

JEL Classification: C68, D58, H22, Q43

Keywords: general equilibrium, CGE models, climate change policy

\footnotetext{
${ }^{*}$ Corresponding author. Fondazione Eni Enrico Mattei, Castello, 5252, 30122 Venezia, Italy. Tel: +39.041.2711470 Fax: +39.041.2711461 e-mail: elisa.lanzi@feem.it. We thank Carlo Carraro, Enrica De Cian, Ramiro Parrado and seminar participants at the University Ca' Foscari of Venice and FEEM for helpful comments and discussions.
} 


\section{Introduction}

Policies to limit emissions of greenhouse gases (GHG) have been the subject of extensive numerical analysis. The workhorse of such investigations has been computable general equilibrium (CGE) models, whose usefulness lies in their ability to combine economic accounts for a range of industries across different geographic regions within the ArrowDebreu equilibrium framework of interacting markets. The result is a complete and theoretically consistent simulation which captures the full spectrum of economic feedback effects in response to an emission limit.

These advantageous characteristics have been particularly important for the study of the international policies such as the Kyoto Protocol. However, the majority of wellknown CGE simulations (e.g., DART (Klepper, Peterson and Springer [21]), GEM-E3 (Capros et al. [6]), and the widely used GTAP-E (Burniaux and Truong [5])) have been constructed to examine long-run GHG emission-reduction scenarios, and a key assumption of their design is that physical capital is able to move among the economic sectors being modeled as its relative marginal productivities change. A decade ago Jacoby and Sue Wing [18] highlighted the adverse impact that imperfect "malleability" of capital can have on the short-run macroeconomic costs of U.S. compliance with its erstwhile Kyoto emission target. A more recent investigation by Sue Wing [32] in the context of the "technology substitution" commonly seen in bottom-up engineering simulations confirmed the crucial role played by imperfect malleability of capital among sectors and activities in determining the costs of carbon taxes. These studies raise two key questions:

- How malleable is capital likely to be over the time-frame that emission limits such as Kyoto are anticipated to bind? And,

- To what extent do various characteristics of abating economies influence the magnitude of the short-run cost premium to which capital rigidities gives rise?

This paper is a preliminary attempt to answer the second question, and to assess the im- 
plications of our findings for the distribution of the costs of compliance with the European Union Emission Trading Scheme (EU-ETS).

Our approach draws on the theoretical literature arguing that capital, once invested in a sector, cannot be redeployed in other sectors of the economy and easily adjust to changes in relative prices. This view is supported by the works of Johansen [19], Bliss [2] and Gapinksi [14] who point out the difference between putty-putty capital, that is capital that can readjust between sectors, and putty-clay capital, that cannot readjust. The former is perfectly malleable capital, whereas the latter is imperfectly malleable.

We construct an analytical general equilibrium model of a simple two-sector economy following Harberger [15]. In the model, one sector only uses capital input (the "clean" sector), whereas the other sector uses capital as well as a polluting input (the "dirty" sector). We then adapt this simple "clean-dirt" sector model to the case of imperfect malleability of capital, which we use to compare the effects of a tax levied on the polluting input in the dirty industry. To gain insight into the likely magnitudes of these effects, we then use economic data from the EU member states to numerically parameterize the model, treating fossil fuels as the dirty input. Finally, we compare these results to the output of a CGE simulation of the EU-ETS.

Our results indicate that environmental taxation is more effective at reducing pollution when capital is perfectly malleable and can costlessly switch from the dirty to the clean sector. While the analytical model presents a general solution to this problem, which is based on parameter values, a numerical analysis using EU data yields determinate conclusions regarding the effects of a carbon tax on the main economic variables. We find that the imposition of a carbon tax is more effective in the reduction of pollution under conditions of perfect malleability of capital. Finally, the CGE model is used to perform a policy-relevant study and to identify secondary effects that cannot be seen in any of the previous analyses. Although the ETS target is met in both simulations related with the two scenarios of capital malleability, it is found that there is a much stronger 
carbon leakage effect under imperfect malleability of capital. This paper shows how the three levels of analysis can contribute to understand the influence of capital malleability on the effectiveness of carbon regulations. Thus, in evaluating short-run climate policies it is crucial to take into consideration the degree of malleability of capital.

The paper is organized as follows. Section 2 presents the theoretical models and their predictions. Section 3 shows the numerical application of the theoretical models. Section 4 illustrates the applied CGE model and its application to the EU-ETS. Section 5 concludes.

\section{A Simple Theoretical Model}

Our investigation of capital malleability begins with a simple two-sector tax incidence model in which capital is the only factor of production. In our test-bed economy, household are modeled as representative agent who derives utility $(U)$ from consumption of a clean good $\left(X_{C}\right)$ and a dirty good $\left(X_{D}\right)$, which is offset by the disutility of exposure to pollution $(Z)$. The sector which produces the clean good uses capital $\left(K_{C}\right)$ exclusively, while the output of the dirty sector is produced using inputs of capital $\left(K_{D}\right)$ and pollution $(Z)$. The prices of the clean and dirty goods are given by $P_{C}$ and $P_{D}$. The agent is endowed with a fixed stock of capital $(K)$, which she rents out to the sectors in exchange for factor income. We examine the effects of a shock in the form of an exogenous pollution tax $\left(\tau_{Z}\right)$, and compare the economy's response when capital is intersectorally mobile and when it is fixed. ${ }^{1}$

\subsection{Households}

The representative agent's utility is increasing in consumption and decreasing in pollution, and can be written $U=U\left(X_{C}, X_{D}, Z\right)$, with $U_{X_{C}}, U_{X_{D}}>0$ and $U_{Z}<0$. The impact of the tax on households' welfare operates through two channels: the market effects of

\footnotetext{
${ }^{1}$ A more sophisticated model with two factors of production is developed in Appendix A. Its conclusions are similar to the ones we derive below.
} 
changes in goods consumption and the non-market effect of mitigating the disutility of pollution. To simplify the analysis we adopt Bovenberg and de Mooij's [3] assumption that consumption and pollution are separable. We assume that pollution negatively affects utility through an environmental damage function $\mathcal{E}(Z)$, where $\mathcal{E}_{Z}<0$. This allows us to totally differentiate $U$ to get

$$
d U=\left[U_{X_{C}} d X_{C}+U_{X_{D}} d X_{D}\right]+U_{Z} \mathcal{E}_{Z} d Z
$$

The term in square braces as the market-mediated change in welfare due to the pollution tax, while the last term is the non-market impact.

The components of welfare change may be elaborated by examining the agent's optimal consumption decision. Letting $M$ denote aggregate income, the agent's utility maximization problem is

$$
\max _{X_{C}, X_{D}}\left\{U\left(X_{C}, X_{D}, Z\right) \mid P_{C} X_{C}+P_{D} X_{D} \leq M\right\}
$$

The first order conditions equate the marginal utility of consumption of the two goods to the Lagrange multiplier $(\mu)$, whose natural interpretation is the marginal utility of income:

$$
U_{X_{C}} / P_{C}=U_{X_{D}} / P_{D}=\mu
$$

Using this relation to substitute for the marginal utilities on the right-hand side of $d U$ yields

$$
d U=\left[\mu P_{C} d X_{C}+\mu P_{D} d X_{D}\right]+U_{Z} \mathcal{E}_{Z} d Z
$$

We simplify this by letting $U_{Z} \mathcal{E}_{Z} / \mu=-\delta$ denote the marginal disutility of environmental damage, dividing both sides by the level of income, and multiplying and dividing each 
differential on the right-hand side by its corresponding quantity level:

$$
\frac{d U}{\mu M}=\left[\frac{P_{C} X_{C}}{M} \frac{d X_{C}}{X_{C}}+\frac{P_{D} X_{D}}{M} \frac{d X_{D}}{X_{D}}\right]-\delta \frac{Z}{M} \frac{d Z}{Z}=\left[(1-\phi) \hat{X}_{C}+\phi \hat{X}_{D}\right]-\delta \zeta \hat{Z} .
$$

The left-hand side of this expression is the dollar value of the change in utility divided by initial income. This is a dimensionless index of the total welfare effect of the tax, which we denote $\hat{W}$. On the right-hand side, $\phi$ is the initial budget share of the dirty good, $\zeta=Z / M$ is the initial pollution intensity of GDP, and we follow Fullerton and Metcalf [13] in using a "hat" $(\wedge)$ over a variable to indicate its logarithmic differential. ${ }^{2}$

Eq. (1) provides insights into the welfare but has no bearing on the solution to the model. The latter requires us to make assumptions about households' preferences. We model the representative agent as having constant elasticity of substitution (CES) utility function in which the two goods substitute for one another with an elasticity of substitution, $\sigma_{U}$. Then, the definition of the elasticity implies the following relationship between the prices and quantities of commodities in log-differential form:

$$
\hat{X}_{C}-\hat{X}_{D}=\sigma_{U}\left(\hat{P}_{D}-\hat{P}_{C}\right)
$$

\subsection{Producers}

Turning to the supply side of the economy, we assume that each good is produced according to a homogeneous-of-degree-one technology, which we express using the production functions $X_{C}=f_{C}\left(K_{C}\right)$ and $X_{D}=f_{D}\left(K_{D}, Z\right)$. The assumptions of free entry and competitive markets for inputs and output then imply that each sector's revenue just equals its expenditures on inputs. We express this using the zero-profit conditions $P_{C} X_{C}=r_{C} K_{C}$ and $P_{D} X_{D}=r_{D} K_{D}+\tau_{Z} Z$, in which $r_{C}$ and $r_{D}$ are the rental rates of capital in each sector.

\footnotetext{
${ }^{2}$ e.g., $\hat{z}=d \log z=d z / z$.
} 
Log-differentiation of the production functions and zero-profit conditions yields:

$$
\begin{aligned}
\hat{X}_{C} & =\hat{K}_{C} \\
\hat{X}_{D} & =\theta \hat{Z}+(1-\theta) \hat{K}_{D} \\
\hat{P}_{C}+\hat{X}_{C} & =\hat{r}_{C}+\hat{K}_{C} \\
\hat{P}_{D}+\hat{X}_{D} & =\theta\left(\hat{\tau}_{Z}+\hat{Z}\right)+(1-\theta)\left(\hat{r}_{D}+\hat{K}_{D}\right)
\end{aligned}
$$

where $\theta=\tau_{Z} Z /\left(P_{D} X_{D}\right) \in(0,1)$ is the share of pollution in the cost of dirty production. As well, we assume that the dirty sector employs CES production technology, treating capital and pollution as substitutes with an elasticity of substitution $\sigma_{D}$. The definition of the elasticity yields the log-differential relationship:

$$
\hat{K}_{D}-\hat{Z}=\sigma_{D}\left(\hat{\tau}_{Z}-\hat{r}\right) .
$$

Our model is closed through the specification of the factor market, which differs according to whether or not capital is malleable, in the sense of being intersectorally mobile, or sector-specific. In the malleable case the factor market clears $\left(K=K_{C}+K_{D}\right)$ and the law of one price holds $\left(r_{C}=r_{D}=r\right)$, while in the non-malleable case, sectors' endowments of capital are fixed. Letting $\lambda=K_{D} / K \in(0,1)$ denote the share of malleable capital in the dirty sector, we may take the log-differential of the market clearance condition in each case to obtain

$$
\begin{aligned}
0 & =\lambda \hat{K}_{D}+(1-\lambda) \hat{K}_{C}, \\
\hat{K}_{i} & =0 \quad i=C, D .
\end{aligned}
$$

The welfare index (1) must be appropriately normalized to accommodate the different capital market closures. Under malleable and sector-specific capital, aggregate factor income is $r K$ and $r_{C} K_{C}+r_{D} K_{D}$, respectively. In each case, setting the initial values of the 
rental rates to unity $\left(r=r_{C}=r_{D}=1\right)$ allows us to equate GDP with the capital endowment $(M=K)$ and treat $\zeta$ as the initial pollution-capital ratio.

In the malleable case, our model consists of eqs. (2)-(7) and (8a), along with the condition $r_{C}=r_{D}=r$, which yields a system of seven equations in eight unknowns $\left(\hat{P}_{C}, \hat{P}_{D}\right.$, $\left.\hat{r}, \hat{X}_{C}, \hat{X}_{D}, \hat{Z}, \hat{K}_{C}, \hat{K}_{D}\right)$. In the sector-specific case, our model consists of eqs. (2)-(7) and (8b), which is a system of eight equations in nine unknowns $\left(\hat{P}_{C}, \hat{P}_{D}, \hat{r}_{C}, \hat{r}_{D}, \hat{X}_{C}, \hat{X}_{D}, \hat{Z}\right.$, $\left.\hat{K}_{C}, \hat{K}_{D}\right)$. To solve the model we first designate $X_{C}$ as the numeraire by setting $\hat{P}_{C}=0$, and then find a solution to the system as a function of an increase in the pollution tax $\hat{\tau}_{Z}$. In each case, eq. (1) is employed ex-post to evaluate the welfare effects of a small change in the tax.

\subsection{Results}

The solutions to both models are straightforward to obtain, and are summarized in Table $1 .^{3}$ The increase in the emission tax has an unambiguous effect on a few variables in the economy. Irrespective of capital malleability, the tax reduces pollution, raises the dirty good's price and reduces its production and consumption. For the remaining variables in the model, the effect of the tax depend on both the degree of capital malleability and the values of the parameters-in particular the difference between the elasticities of substitution for the consumer and for the dirty producer. When $\sigma_{U}>\sigma_{D}$ the results are consistent with simple intuition, but it is less so when the opposite is true.

The clean good's production is unaffected when capital is sector-specific, and changes

\footnotetext{
${ }^{3}$ We deal first with the malleable case. After price normalization, eqs. (3) and (5) imply that $\hat{r}=0$. Combining (4) and (6) yields $\hat{P}_{D}=\theta \hat{\tau}_{Z}$, which we plug into (2) to obtain $\hat{X}_{D}=\hat{K}_{C}-\sigma_{U} \theta \hat{\tau}_{Z}$. Substituting this result back into (4) yields $\hat{K}_{C}-\theta \hat{Z}-(1-\theta) \hat{K}_{D}=\sigma_{U} \theta \hat{\tau}_{Z}$, which we simplify by exploiting the fact that (8a) implies that $\hat{K}_{C}=\lambda /(\lambda-1) \hat{K}_{D}$. This leaves us with two equations, $(1-\theta+\lambda \theta) /(1-\lambda) \hat{K}_{D}+\theta \hat{Z}=$ $-\sigma_{U} \theta \hat{\tau}_{Z}$ and eq. (7), in two unknowns, $\hat{K}_{D}$ and $\hat{Z}$, the solution to which allows us to recover expressions for the remaining variables.

Turning to the non-malleable case, (8b), (3) and (5) together imply that $\hat{K}_{C}=\hat{K}_{D}=\hat{X}_{C}=\hat{r}_{C}=0$, which collapses the system to simplified versions of eqs. (2), (4), (6) and (7). We use (7) to eliminate $\hat{Z}$ in (4) and (6). The former becomes $\hat{X}_{D}=\sigma_{D} \theta\left(\hat{r}_{D}-\hat{\tau}_{Z}\right)$, which we then plug into (2) and (6), leaving us with two equations, $\hat{P}_{D}=\theta \hat{\tau}_{Z}+(1-\theta) \hat{r}_{D}$ and $\sigma_{D} \theta\left(\hat{\tau}_{Z}-\hat{r}_{D}\right)=\sigma_{U} \hat{P}_{D}$, in two unknowns, $\hat{r}_{D}$ and $\hat{P}_{D}$, the solution to which allows us to recover expressions for the remaining variables.
} 
equivocally when it is malleable, increasing if $\sigma_{U}>\sigma_{D}$, and decreasing otherwise. Symmetrically, the capital rental rate is unaffected in the malleable case and in the clean sector in the sector-specific case. The rental rate in the dirty sector decreases if $\sigma_{U}>\sigma_{D}$, and increases otherwise. Capital mobility leads to induced changes of opposing signs in the two sectors' demands for capital, with the clean (dirty) sector's capital increasing (decreasing) if $\sigma_{U}>\sigma_{D}$, and vice versa.

The welfare effects of the tax turn out to be more transparent in the case where sectors have fixed capital stocks. Then, welfare improves so long as the dollar-denominated marginal environmental damage $(\delta \zeta)$ exceeds the marginal benefit of pollution to households, which is indicated by the product of pollution's initial cost share in dirty production and the dirty good's initial share of household expenditure $(\theta \phi)$. When capital is malleable the outcome is more complicated, with welfare increasing if marginal damage exceeds a threshold given by $\delta \zeta>\frac{\theta\left(\sigma_{U}-\sigma_{D}\right)(\phi-\lambda)}{\theta(1-\lambda) \sigma_{U}+(1-\theta(1-\lambda)) \sigma_{D}}$, a condition which is satisfied if $\sigma_{U} \gtrless \sigma_{D}$ and $\lambda \gtrless \phi$.

The intuition behind the equivocal results is as follows. A low value of $\sigma_{U}$ implies that households' commodity demands are relatively inelastic, with consumption of the dirty good declining only slowly as its price increases, while a high value of $\sigma_{D}$ means that the level of production in the dirty sector can be easily maintained by substituting capital for pollution as the tax increases the latter's price. If capital is sector-specific, then the dirty sector's scope for input substitution is constrained by its perfectly inelastic capital supply, with the result that the fall in the quantity of pollution bids up the marginal product of capital. But if capital is intersectorally mobile, ease of input substitution in the dirty sector will increase the demand for capital, and will end up drawing capital away from the clean sector.

In the reverse situation with a high value of $\sigma_{U}$ and a low value of $\sigma_{D}$, household demands for commodities are relatively elastic and the dirty sector's input demands are relatively inelastic. The tax-induced increase in the cost of pollution, combined with capi- 
tal's limited substitutability, increases the dirty good's cost while leaving the unit demand for capital relatively unaffected. The price-sensitivity of the households' demand for the output of the dirty sector then causes the latter to decline, along with the demand for capital. This process releases capital to the clean sector, enabling its output to expand to substitute for the fall in households' dirty consumption.

Given these dynamics, a natural question is whether the impacts of the tax are largeror, indeed, of the same sign-if capital is malleable rather than intersectorally immobile. The change in price of the dirty good is higher where capital is perfectly malleable. Furthermore, malleability results in larger declines in dirty production and pollution good if:

$$
\left(\lambda \sigma_{D}+(1-\lambda) \sigma_{U}\right)\left(\theta \sigma_{D}+(1-\theta) \sigma_{U}\right)>\sigma_{D} \sigma_{U}
$$

and

$$
\left[\theta(1-\lambda) \sigma_{U}+(1-\theta(1-\lambda)) \sigma_{D}\right]\left(\theta \sigma_{D}+(1-\theta) \sigma_{U}\right)>\sigma_{D} \sigma_{U}
$$

respectively. This solution is hard to interpret analytically, but it is possible to study it graphically by considering different combination of parameter values. In Figure 1 the white (gray) areas correspond to parameter values for which the effect on the variable is greater under perfect (imperfect) malleability of capital ${ }^{4}$.

From Figure 1.A it is possible to see that the effect of a carbon tax on $\hat{X}_{D}$ depends mostly on the values of the elasticities of substitution. If $\sigma_{U}>\sigma_{D}\left(\sigma_{U}<\sigma_{D}\right)$ capital malleability results in larger (smaller) declines in dirty production if $\theta$ and $\lambda$ are low (high). Thus, if in the economy it is easier to substitute production from the dirty good towards the clean good $\left(\sigma_{U}>\sigma_{D}\right)$, production in the dirty sector declines more under perfect capital malleability unless the dirty sector is at the same time highly polluting and capital intensive. Given that the dirty sector is generally small, it is likely that the production if the dirty good decreases more when capital is perfectly malleable.

\footnotetext{
${ }^{4}$ The graphs are drawn considering the contours of the ratio of the absolute value of the variables under the two assumptions and determining where it is greater or smaller than one.
} 
The effect on the pollution good is greater under perfect capital malleability mainly for high values of $\sigma_{U}$. For low values it is always greater under imperfect capital malleability. For intermediate values of the elasticities, the decline in pollution is greater under perfect capital malleability if $\theta$ and $\lambda$ are low. Again, the intuition is that production is reallocated to the clean sector if capital is mobile and at the same time the economy is elastic. Whereas, adjustment is made within the dirty sector if capital is not mobile and the elasticity of substitution between production factors in the dirty sector is high.

Finally, the impact on welfare is larger under perfect capital malleability if the following condition is satisfied:

$$
\left\{\delta \zeta \sigma_{D}+\theta\left(\sigma_{U}-\sigma_{D}\right)[\lambda(1-\phi)+(\delta \zeta-\phi)(1-\lambda)]\right\}\left(\theta \sigma_{D}+(1-\theta) \sigma_{U}\right)>\sigma_{D} \sigma_{U}(\delta \zeta-\theta \phi)
$$

This is complicated condition can be simplified considering that the environmental damage $(\delta \zeta)$ is very small ${ }^{5}$ and that it is likely offset by the environmental benefits gained from the reduction in pollution. By imposing $\delta \phi=0$, we obtain a simpler condition:

$$
\frac{\theta\left(\sigma_{U}-\sigma_{D}\right)(\lambda-\phi)\left(\theta \sigma_{D}+(1-\theta) \sigma_{U}\right)}{\sigma_{D} \sigma_{U} \theta \phi}>0,
$$

showing that welfare effects are higher under perfect capital malleability if $\sigma_{U} \gtrless \sigma_{D}$ and $\lambda \gtrless \phi$. This is the same condition under which the welfare impacts are positive under perfect malleability of capital.

In this simple model the results are highly dependent on the values of the elasticities of substitution and the shares describing the size and characteristics of the dirty sector. Where the economy is more flexible in the reallocation between the two sectors and where capital is malleable, a carbon tax results in the reduction of input investments in the production of the pollution goods, and thus in lower production of the good itself. This is with the exception of the instance in which the dirty sector is very large and very capital

\footnotetext{
${ }^{5}$ Estimates by Newell and Pizer [25] give a value of approximatively $9.2^{*} 10^{-} 13$.
} 
intensive, so that there is large scope for substitution between inputs in the dirty sector. Where the economy is less elastic but the production of the dirty good is elastic, then the effects on the economic variables are stronger under imperfect malleability of capital, which favors reallocation of inputs in the dirty sector.

\section{Numerical analysis}

The simple model illustrated achieves only parameter-dependent results. We now perform a numerical analysis in order to obtain conclusions on whether a carbon tax has a positive or negative impact on the key variables of the model, and on the difference in magnitude of these effects under the two assumptions on capital malleability ${ }^{6}$. This will be done using reliable parameter values ${ }^{7}$.

The share parameters $(\theta, \lambda$ and $\phi)$ are calculated from the GTAP6 database ${ }^{8}$ and are illustrated in Table 2. The dirty industry is represented by sectors covered by the EU ETS, namely refined coal and petroleum, pulp and paper, electric power, non-metallic mineral products and, iron and steel. All other sectors are considered to be part of the clean sector. Although no sector is fully clean, these sectors have a very small amount of dirty input $Z$, which can be disregarded and summed to the other inputs. The dirty inputs that correspond to the pollution good $Z$ in the model, are fossil-fuel inputs (i.e. coal, gas and oil).

Results for the production and input variables depend on the values of the share parameter $\theta$ and $\lambda$, which are illustrated graphically in Figure 2. The share of polluting input in the production of the dirty good $\theta$ ranges from .03 to .46 , while the share of cap-

\footnotetext{
${ }^{6} \mathrm{~A}$ numerical analysis has been performed for the model with two production factors. Results are in Annex I.

${ }^{7}$ Fullerton and Heutel [12] perform a similar analysis but for the US only.

${ }^{8}$ This is the database related to the Global Trade Analysis Project (Dimaranan and McDougall [9]). It contains data related to 87 world countries/regions and 57 economic sectors. As the focus of this paper is on European countries the database has been aggregated to 25 regions, leaving European countries disaggregated while aggregating the rest of the world. Regional and sectoral aggregations will also be used in the CGE model in Section 4 and are described respectively in Tables 8 and 9.
} 
ital invested in the dirty sector $\lambda$ ranges from .06 to .24 . Thus, the dirty sector usually represents a small share of the economy, and most capital is invested in the clean sector. Fullerton and Heutel [12] also perform a numerical analysis and calibrate their parameters according to stylized facts and data on the US economy. In fact, they assume that labor and capital invested in the clean industry is 0.8 , and that the expenditure in pollution in the dirty industry is .25 . These are similar to our results, as the share of capital invested in the clean industry in the NAFTA region is .82, and the expenditure in pollution in the dirty industry is $.07^{9}$. Figure 2 shows that for most countries/regions, the parameter $\theta$ has higher values than $\lambda$. The only countries for which this is not true are Ireland, Switzerland and the region Rest of Europe. These are the countries in which a relatively high percentage of capital is invested in the dirty sector and in which the share of the polluting input is particularly small.

For what regards the elasticities of substitution, following Fullerton and Metcalf [13], the substitution elasticity in consumption between the clean and dirty good is assumed to be $1\left(\sigma_{U}=1\right)$ and the elasticity of substitution between inputs in the dirty industry is assumed to be $.5\left(\sigma_{D}=.5\right)$. In the calculations the value of the tax increase is $10 \%$, as in Fullerton and Heutel [12]. This is an arbitrary value that still allows us to study the different conclusions that the two models reach. Finally, estimates of marginal environmental benefits from $\mathrm{CO}_{2}$ reduction by Newell and Pizer [25] are of around $9.2^{*} 10^{-13} \$ /$ ton $\mathrm{CO}_{2}$. This means that the value of $\delta \phi$ is very close to zero.

Table 2 illustrates results for the numerical analysis of the two models. Results reflect the predictions of the theoretical model for the case in which $\sigma_{U}>\sigma_{D}$. In the case of perfect malleability of capital, as expected, production of the clean good increases, while that of the dirty good decreases. Pollution $Z$ also decreases as a consequence of the carbon tax. Results on the reduction in pollution are similar to those obtained by Fullerton and Heutel [12]. They find that a $10 \%$ increase in the tax yields to approximately a $6 \%$

\footnotetext{
${ }^{9}$ The fact that expenditure in pollution is lower can be explained by the difference in assumptions about the dirty inputs.
} 
increase in pollution, which is in the range of the calculations for pollution changes illustrated in Table 2 . Countries with higher pollution intensity (higher $\theta$ ), such as Russia and the rest of Former Soviet Union, the Netherlands and Belgium, achieve a bigger amount of pollution reduction. Countries with a large dirty sector instead (large $\lambda$ ), such as Ireland, tend to achieve a lower amount of emissions reductions. In the case of imperfect malleability of capital, results are also as expected, with no changes in the clean industry and a decrease in the production of the dirty good and in the use of the polluting input.

For what regards welfare, results depend also on the value of the parameter $\phi$, namely the share of household expenditure in the dirty good. Where expenditure in the dirty good is very small welfare changes can be positive under perfect malleability of capital. Without capital mobility instead, the change in welfare is always negative.

Comparing results under the two assumptions it is possible to see that the carbon tax has a higher effect in the case of perfect capital malleability. In fact, in this case there is a more effective re-adjustment of production patterns and a higher reduction of pollution. Welfare increases in some cases under perfect capital malleability. With the exception of Denmark and Switzerland, welfare decreases more under imperfect malleability of capital. For most countries/regions, the same carbon tax is more effective in terms of emissions reductions, welfare and benefits from the improved environmental quality under perfect malleability of capital.

It is interesting to check the impact that the structure of the economy has on the results. This can be done by analyzing the relationship between the parameter values ( $\lambda$ and $\theta)$ and the difference in the variable changes between the case of perfect and imperfect malleability of capital, as illustrated in Figure 3. Only a few countries with differing parameter values are presented in the graph. Ireland is the only country with a a high capital share invested in the dirty good and a very low pollution intensity of the dirty sector. It is in fact the country in which the difference in pollution reduction between the two capital malleability scenarios is smaller. At the same time the difference in the 
decreases in the production and price of the dirty good is higher. Another interesting case is that of the Netherlands, where the dirty sector has a high level of pollution intensity and a low investment of capital. In this country the difference in pollution reduction is the highest while the difference in production and price is the between the lowest. This is because the high pollution intensity favors reallocation of capital to the clean sector, and this is not possible when capital is immobile. In general the higher the pollution intensity the higher the difference in the results between the two capital malleability scenarios. Also, the higher share of capital invested in the dirty sector, the lower the difference in the results. This is because in this case reallocation of inputs in the dirty sector is favored, and thus the immobility of capital has a lower effect on the results.

The results from the numerical analysis allow us to reach conclusions on a realistic outcome of the model presented in Section 2. Nonetheless, these results are limited for a number of reasons. First, it does not take into account adjustments taking place via international trade. . Secondly, the dirty sector is in large part corresponding to inputs that are usually used to produce the clean good. Thus, a more complicated production structure would lead to a more realistic picture. Finally, the same carbon tax has been applied to all countries and world regions considered, even though a harmonized carbon tax is very hard to implement from the political point of view. A policy-relevant study would also include the possibility to study the effects of the imposition of asymmetric environmental regulations would have on the countries subject to the regulation as well as those that are not. It is not possible to capture these effect in a simplified model and in the numerical analysis of it. CGE models instead offer the possibility to take into account these issues, as they allow us to calculate the equilibrium of a multi-region and multisector model. The next section will explain the use of CGE models and give an example of a policy study. 


\section{CGE Application}

\subsection{Model Structure}

The advantage of CGE models is that they make it possible to apply real data to multicountry and multi-sector general equilibrium models, so that it is possible to study the effects of policies, such as a carbon tax or carbon trading. In this section, a study of the EU ETS will be used to verify whether the assumption of perfect capital malleability influences policy conclusions. The model employed for the policy simulations is a static multiregion CGE based on Harrison, Rutherford and Tarr [16], outlined in Rutherford [29]. This model is a coherent and extended version of the model presented in Section 2. Thus, all policy results will be relevant for comparison to the theoretical model.

The model divides the world into 25 regional economies $r \in R$, each of which contains one representative agent, and 14 industries $j \in J^{10}$. Agents are endowed with labor and capital, which are internationally immobile. They rent out these resources to domestic industries in return for factor income. Each industry produces a single homogenous output good $i \in I$, demanded by other sectors and the representative agent. The economies are linked by bilateral goods trade according to the Armington [1] assumption, whereby regions' exports of a given commodity are differentiated, and the use of each commodity is given by a constant elasticity of substitution (CES) composite of domestically-produced and imported varieties of that good.

Agents minimize expenditure and, as in the previous sections, are assumed to have a Cobb-Douglas utility function and a constant marginal propensity to save out of their income. The government is explicitly represented, though it has a passive role. It is modeled as a cost-minimizing firm using commodities to produce an aggregate government good. Industries are modeled as cost-minimizing representative firms whose technology is given as a nested CES production function. The production function parametrization

\footnotetext{
${ }^{10}$ See Tables 8 and 9 for for description of the regional and sectoral disaggregation respectively
} 
differs across sectors, but it has the common structure illustrated in the diagram in Figure 4. The inverted tree represents the sub-production function. At the top level, output $Y_{j, r}$ is produced from materials, every value-added and a fixed resource factor according to a CES production function with an elasticity of substitution $\sigma_{j}^{Y}=.5$. Note that this is equivalent, though more complicated, to the elasticity of substitution $\sigma_{D}$ used in the previous sections. In fact, $\sigma_{j}^{Y}$ is the elasticity of substitution in production between clean inputs, such as value-added and some of the materials which derive from clean industries, and dirty inputs such as other materials deriving from dirty industries. This structure implies a limited capability of firms to substitute intermediate goods, labor and capital with natural resources, especially in the short-run. In the second level, the left nod represents the production of value-added from a Cobb-Douglas production function of inputs of capital $K_{j, r}$ and labor $L_{j, r}$. The intermediate nod represents the production of aggregate energy inputs to each sector $j$. These are generated by a CES sub-production function of intermediate energy commodities $X_{e, j, r}$ (energy sectors are indexed by $e \subset i$ ) and combined according to the interfuel elasticity of substitution $\sigma_{j}^{E}$. The right nod represents aggregate material input to each sector that is generated by a Leontief sub-production function of intermediate non-energy goods $X_{n, j, r}$ (non-energy sectors are indexed by $n \subset i$ ). The third and fourth levels of the diagram represent the two-level Armington aggregation process for each intermediate input. For the production of each good $j$, intermediate input $X_{i, j, r}$, is a CES composite of domestically-produced $X_{n, j, r}^{D}$ and imported varieties $X_{n, j, r}^{M}$ according to the Armington elasticity of substitution $\sigma_{i}^{D M}$. The imported component is itself a CES aggregate of $r^{\prime}$ s imports of commodity $i$ from other regions according to the interregional elasticity of substitution $\sigma_{i}^{M M}$.

The present model is particularly constructed for the analysis of carbon policies. In fact, the present hierarchical production function reflects the difficulty of substituting material inputs for energy and, to a lesser extent, low-carbon energy inputs such as natural gas for carbon-intensive fuels such as coal in the short-run. While data are not available 
on the technologies employed by covered sector installations and combustion units in the non-covered industries, it seems doubtful that a large fraction of these sources processes fuel-switching capability. On the other hand, there is ample evidence of fuel-switching capability (see Soderholm [30]). The parameter $\sigma_{j}^{E}$ was thus set at a low value in all industries except the electricity sector.

A novel feature of this model is its ability to account for $\mathrm{CO}_{2}$ emissions produced by the fossil fuel combustion installations which are regulated by the EU-ETS but are located in industries outside the program's covered sectors. In fact, for the policy simulations actual emissions of $\mathrm{CO}_{2}$ will be linked to the use of energy. As shown in Figure 4, emissions associated with the intermediate use of each fossil fuel must be covered by allowances $A$, but this occurs only in the "covered" and "combustion" sectors (see sectoral aggregation in Table ?? in Annex II. Denoting the set of covered industries by Z, for each industry $z \in Z$, the use of domestic and imported inputs of energy goods $e$ are given by $A_{e, z, r}^{D}=\varepsilon_{e, z, r} \omega_{z, r} X_{e, z, r}^{D}$ and $A_{e, z, r}^{M}=\varepsilon_{e, z, r} \omega_{z, r} X_{e, z, r}^{M}$ respectively, where $\varepsilon_{e, z, r}$ is $e^{\prime} \mathrm{s}$ region- and sector-specific emission factor and $\omega_{z, r}$ is the fraction of that industry's emissions covered by policy. In the fully covered sectors $\omega_{z, r}=1$, while in the combustion sectors, combustion installations account for less than the total quantity of emissions, so that $0<\omega_{z, r}<1^{11}$. Each of these sectors' total emissions are thus given by the sum of domestic and imported emissions, $A_{e, z, r}^{D}+A_{e, z, r}^{M}$. The imposition of a cap to allowances across participating regions $s \in S \subseteq R$ and the set of covered and combustion sectors $Z$ is given by the constraint:

$$
\sum_{e} \sum_{z \in Z} \sum_{s \in S}\left[A_{e, z, s}^{D}+A_{e, z, s}^{M}\right] \leq \sum_{s \in S} \bar{A}_{s}
$$

where $\bar{A}_{s}$ is the maximum amount of allowances assigned to region $s$. The dual to the expression above is the market clearing price of allowances.

\footnotetext{
${ }^{11}$ Only a fraction of the combustion sector is covered by the EU ETS. This correspond to the Large Combustion Plants (LPC).
} 


\subsection{Model Formulation and Calibration}

The CGE model formulates the general equilibrium problem of equalizing demand and supply simultaneously across all markets as a mixed complementarity problem, or MCP (see Mathiesen [24], Rutherford [27]). Cost minimization by the industries and expenditure minimization by the representative agent in each region give rise to vectors of demands for commodities and factors. Demands are functions of domestic factor prices, domestic and international commodity prices, industries' activity levels, and the income levels of the regional representative agents. These demands are combined with the general equilibrium conditions of market clearance, zero-profit and income balance. This yields to a square system of non-linear inequalities that forms the aggregate excess demand correspondence of the world economy (cf. Sue Wing [31]). This system is numerically calibrated and expressed as an MPC using the MPSGE subsystem (Rutherford [28]) for GAMS (Brooke et al. [4]), and solve using the PATH solver (Dirkse and Ferris [11]).

The benchmark dataset, as in Section 4, is the GTAP6 database (Dimaranan and McDougall [9]). This database is a snapshot at the world economy in 2001. Data from bilateral trade, transport and protection data are combined with individual country social accounting matrices and energy balances in order to constitute an approximation of the world economy as if it were in a full economic equilibrium. The original dataset contains 87 world regions and countries, and 57 sectors, but it has been aggregated to the 25 regions and 14 sectors described in Annex II. Elasticity of substitution between energy inputs is assumed to be .5, elasticities of substitution between domestic and imported intermediate products range from .3 to 11.0 according to the different products, and elasticities of substitution of intermediates across regions range from 3.8 to 33 . These are adapted from from Dimaranan, McDougall and Hertel [10] and are assumed to be the same across regions. A baseline projection of economic activity in 2010 was prepared by scaling the endowments in each region according to the historical growth rates of GDP from 2001 to 2007, and forecasts of GDP growth for the period 2008-2010 from the 2007 


\section{IMF World Economic Outlook.}

The emission coefficients that link $\mathrm{CO}_{2}$ emissions to the model's projection of economic activity were computed by first estimating emissions by sector and fuel for each region based on the International Energy Agency (IEA) energy balances for 2001 following Lee (2002), and then dividing quantities of emissions by the economic values of the corresponding flows of fossil fuels given in the GTAP6 database. The result is a consistent set of relationships between the economic quantities of the sectoral demand for fossil fuels and their associated $\mathrm{CO}_{2}$ emissions for the benchmark year. It is assumed that this continues to hold throughout the period of operation of the EU ETS ${ }^{12}$.

Some assumptions were required to estimate the sector coverage. For each combustion sector, it has been necessary to estimate the share of total $\mathrm{CO}_{2}$ emissions that were attributable to large combustion installations. The only data available in the regard were the 2001 IEA energy statistics on countries' emissions from "unallocated producers" (that is generators of electricity or heat for own consumption, as opposed to for sale) whose use of fossil fuels had not been apportioned between industrial and "other" sectors. Accordingly, unallocated producers have been treated as representing emissions of combustion installations in all of the combustion sectors in each country. The average proportion has been calculated for each country and used to assign the amount of emissions from unallocated producers. Although using the average value is not very realistic, the limitations of the data make it impossible to capture sectoral heterogeneity.

The final component of the calibration procedure is aimed at accounting for the high international crude oil and natural gas prices, which are expected to be a key factor in the abatement of emissions and in the trading of allowances. Preliminary runs of the models showed the prices of oil and gas in the European countries falling in real terms over the period 2001-2010, when world prices have been increasing. To remedy this situation supplies of the fixed factor in the oil and gas sectors in the NAFTA and Rest of the World

\footnotetext{
${ }^{12}$ This is equivalent to assuming no autonomous energy efficiency improvement (AEEI) over period 20012010.
} 
regions have been reduced, and fixed factor supplies have been restricted in the remaining regions. As a result, import prices of these commodities in European countries are 90-100 percent higher than in the 2001 base year.

\subsection{Policy Scenarios and Results}

The chosen policy for simulation is the European Union (EU) Emissions Trading Scheme (ETS), as this is the most relevant carbon policy in Europe, and thus it has a high policyrelevance. The EU ETS has been designed to be divided into two phases. Phase I, started in 2004 and finished at the end of 2007, was designed as a kick off trial period to give a chance to the European companies to become confident with emission trading. The emission ceilings for all countries were relatively high and not all EU-25 countries were included, as some only recently entered the European Union. Phase II has started at the beginning of 2008 and will last for a 4-year period up to 2012. The emission ceilings are lower than those of the previous phase and all 25 EU Member States are now included in the trading system. In this section we will present the results from simulations on Phase II, taking the year 2010 as a benchmark case. Two different scenarios will be compared: a baseline scenario, which corresponds to a no-policy at 2010, and an Emission Trading scenario, corresponding to the application of the EU ETS Phase II. Simulations related with imperfect capital malleability are done by imposing making capital fixed and immobile between sectors (sluggish). Emissions ceilings $\bar{A}_{r}$ correspond to the amount of allowances established by the National Allocation Plans (NAP) of the regions included in the ETS (see Table 4). Results for the ETS scenario will be calculated under both assumptions on capital malleability, in order to be able to compare the results. Results on emissions of $\mathrm{CO}_{2}$ from the simulations are illustrated in Table 3.

From Table 3 it is possible to compare emissions from covered (Cov) $)^{13}$, and noncovered (NCov) sectors in the three scenarios considered, namely baseline, ETS with per-

\footnotetext{
${ }^{13}$ Including combustion sector.
} 
fect and imperfect capital malleability. It is clear that emissions are lower in the cases with ETS. However, comparing the two scenarios, emissions are lower in the case of perfect capital malleability, showing, as expected that the environmental policy is more efficient in reducing emissions if there is perfect malleability of capital. Looking at the amount of carbon leakage, that is changes in emissions in countries that are not part of the ETS, it is clear that emissions are higher than in the baseline case. This is because production shifts to places where there are no restrictions on pollution and input costs are lower. The presence of carbon leakage is stronger under the assumption of imperfect capital malleability. In covered sectors, emissions increase strongly in non-EU countries under imperfect malleability of capital. This is because, as there is no possibility of domestic adjustment, countries under the EU ETS will import from abroad. A large amount of carbon leakage may yield to an overall increase in world emissions, which would defeat the purpose of the imposition of climate policies. Furthermore, it may cause a strong decrease in the environmental quality of non-EU countries, which is of particular concern in the case of developing countries. In this countries the risk is to over-exploit the natural resources and thus to a development which is not sustainable over time. Emissions in non-covered sectors instead increase more under perfect malleability of capital. This is coherent with the theoretical results and it reflects the fact that there is more possibility of intra-sectoral adjustment under perfect malleability of capital.

It is also interesting to check on results within the emission trading area, as illustrated in Table 4. Under perfect capital malleability the price of emissions trading is lower $(€ 23.23)$ than the price under imperfect capital malleability (€24.45). This means that costs of reducing the emissions of the amount determined by the ETS cap are higher in the case of imperfect malleability of capital. This is coherent with the theoretical results ${ }^{14}$. Although the price under perfect malleability of capital is higher, it is worth pointing out

\footnotetext{
${ }^{14}$ Whereas in the theoretical model and numerical analysis we have compared the resulting emissions reduction given the same carbon price, here we are comparing carbon prices as resulting from the same emissions reductions. The conclusions reached are the same though, as in a general equilibrium setting price and quantity regulations are equivalent.
} 
that the difference is not very high. Therefore, given the many sources of uncertainty in the price of emission allowances, it appears that capital malleability only influences the carbon price to a relatively small extent. On the other hand, as the issue of capital malleability is known, contrarily to other factors, it should be taken into account in the evaluation of climate policies. The pattern of buyers and sellers is similar in the two cases. The main sellers of permits are countries belonging to the "REU" region, France and Germany. The main buyer instead is the Netherlands, followed by the UK, Finland and Belgium.

This simple exercise with the applied model, has shown how CGE models can contribute to complement economic theory by quantifying the different results that the assumptions on capital may give. CGE can identify secondary-effects, such as carbon leakage, which could have not been calculated with a simple numerical analysis. This section showed how emissions trading is more efficient with perfect capital malleability, not only because more emissions are cut, but also because it leads to a more fair outcome, with a lower amount of carbon leakage.

\section{Conclusions}

This paper has presented a theoretical work on capital malleability in the context of a simple clean-dirty industry model in Harberger style [15], which is used to analyze the effect of climate policies. Results show that a carbon tax is more efficient in reducing emissions under the assumption of perfect capital malleability, although results depend on parameter values. In order to get more determinate results, a numerical analysis has been performed using reliable parameter values. This confirms the expected results that the carbon tax is more efficient under perfect capital malleability. Even though this type of analysis is useful, it does not supply policy-relevant results as the value of the tax is imposed arbitrarily and there are no intra-country adjustments or layered production 
structure. Thus, a policy simulation has been performed using a Computable General Equilibrium model (CGE), based on the EU Emissions Trading System of carbon permits. This analysis also confirms that the environmental policy is more efficient under the assumption of perfect capital malleability.

The contribution of this paper is twofold. First of all, it offers a thorough analysis of the issue of capital malleability and brings to attention the need to consider the differences in results from carbon policy studies in the case of imperfect capital malleability. In fact, this could be particularly relevant in considering policies that are applied in too short a time span for capital to fully adjust between sectors. Secondly, this paper shows how CGE models can contribute to improving and completing a theoretical analysis in adding the possibility to conduct policy-relevant studies and take into consideration many of the several effects that affect the results of climate policies, such as international trade. 


\section{References}

[1] P.S. Armington. A theory of demand for products distinguished by place of production. International Monetary Fund Staff Papers, 16:159-176, 1969.

[2] C. Bliss. On putty-clay. Review of Economic Studies, XXXV:105-132, 1968.

[3] A. Lanz Bovenberg and Ruud A. de Mooij. Environmental levies and distortionary taxation. American Economic Review, pages 1085-1089, 1994.

[4] A. Brooke, D. Kendrick, and A. Meeraus. GAMS: A User's Guide, Release 2.25. The Scientific Press. 1992.

[5] J. Burniaux and T. Truong. GTAP-E: an Energy-Environmental Version of the GTAP Model. GTAP Technical Paper No. 16, Center for Global Trade Analysis. Purdue University, West Lafayette, IN, 2002.

[6] P. Capros, T. Georgakopoulos, S. Zografakis, D. Van Regemorter, and S. Proost. Coordinated versus uncoordinated european carbon tax solutions analysed with gem-e3 linking the eu-12 countries. In S. Proost (editor), Economic Aspects of Environmental Policy, Edware Elgar Publishers, 1997.

[7] W.J. Collins and J.G. Williams. Capital goods Prices, global Capital Markets and Accumulation: 1870-1950. NBER Working Paper 7145, 1999.

[8] P. Corbo and V. Meller. The substitution of labor, skill and capital: its implications for trade and employment. In A. Krueger (editor), Trade and Emplyment in Developing Countries, The University of Chicago Press, Chicago, 1982.

[9] B.V. Dimaranan and R.A. McDougall. Global Trade, Assistance, and Production: The GTAP 6 Data Base. Center for Global Trade Analysis, Purdue Univeristy, 2005. 
[10] B.V. Dimaranan, R.A. McDougall, and T.W. Hertel. Behavioural Parameters. In B.V. Dimaranan and R.A. McDougall, Global Trade, Assistance, and Production: The GTAP 6 Data Base. Center for Global Trade Analysis, Purdue Univeristy, 2005.

[11] S.P. Dirske and M.C. Ferris. The path solver: A non-monotone stabilization scheme for mixed complementarity problems. Optimization Methods and Software, 5:123-159, 1995.

[12] D. Fullerton and G. Heutel. The general equilibrium incidence of environmental taxes. Journal of Public Economics, 91:571-591, 2007.

[13] D. Fullerton and G.E. Metcalf. Environmental controls, scarcity rents, and preexisting distortions. Journal of Public Economics, 80(2):249-267, 2001.

[14] J.H. Gapinski. Capital malleability, macro performance and policy effectiveness. Southern Economic Journal, 52(1):150-166, 1985.

[15] A.C. Harberger. The incidence of the corporation income tax. Journal of Political Economy, 70:215-240, 1962.

[16] G.W. Harrison, T.F. Rutherford, and D. Tarr. Trade Policy Options for Chile: A Quantitative Evaluation. World Bank Policy Research Working Paper 1783, 1997.

[17] T.W. Hertel. Global Trade Analysis: Model and Applications. Cambridge University Press, Cambridge, UK, 1998.

[18] H.D. Jacoby and I. Sue Wing. Adjustment time, capital malleability, and policy cost. Energy Journal, special issue: The Costs of the Kyoto Protocol: A Multi-Model Evaluation:73-92, 1999.

[19] L. Johansen. Substitution versus fixed production coefficients in the theory of economic growth: a synthesis. Econometrica, 27:157-178, 1959. 
[20] R.W. Jones. The structure of simple general equilibrium models. Journal of Political Economy, 73:557-572, 1965.

[21] G. Klepper, S. Peterson, and K. Springer. DART97: A Description of the Multi-regional. Multi-sectoral Trade Model for the Analysis of Climate Policies. Kiel Working Paper No. 1149, 2003.

[22] H.L. Lee. An Emissions Data Base for Integrated Assessment of Climate Change Policy Using GTAP. Draft GTAP Working Paper 16, Center for Global Trade Analysis, Purdue University, West Lafayette, IN, U.S.A., 2002.

[23] C.A.K. Lovell. Ces and ves production functions in a cross-section context. Journal of Political Economy, 81(3):705-720, 1973.

[24] L. Mathiesen. Computation of economic equilibrium by a sequence of linear complementarity problems. Mathematical Programming Study, 23:144-162, 1985.

[25] R. G. Newell and W. A. Pizer. Indexed Regulation. RFF Discussion Paper 06-32, 2006.

[26] S. de A. Pessoa, S. M. Pessoa, and R. Rob. Elasticity of Sustitution between Capital and labor and its Applications to Growth and Development. Pier working paper archive, Penn Institute for Economic Research, Department of Economics, University of Pennsylvania, 2005.

[27] T.F. Rutherford. Applied General Equilibrium Modeling. PhD thesis, Department of Operations Research, Stanford University, 1987.

[28] T.F. Rutherford. Extensions of gams for complementarity problems arising in applied economics. Journal of Economic Dynamics and Control, 19(8):1299-1324, 1995.

[29] T.F. Rutherford. GTAP6inGAMS: The Dataset and Static Model. Paper prepared for the workshop "Applied General Equilibrium Modeling for Trade Policy Analysis in Russia and the CIS", Moscow, Dec. 1-9, 2005. 
[30] P. Soderholm. Fossil fuel flexibility in west european power generation and the impact of system load factors. Energy Economics, 23(1):77-97, 2001.

[31] I. Sue Wing. Cge models for economy-wide policy analysis. MIT Joint Program on the Science and Policy of Global Change technical Note No. 6, 2004.

[32] I. Sue Wing. The synthesis of bottom-up and top-down approaches to climate policy modeling: Electric power technologies and the cost of limiting us $\mathrm{CO}_{2}$ emissions. Energy Policy, 34(18):3847-3869, 2006. 


\section{Annex I}

This section will present a more complete version of the model in which the production factors for both industries are capital $K$, a general production factor $L$ that includes labor, natural resources and land, and pollution $Z$ in the dirty industry. In the case of perfect capital malleability, the resource constraints, already formulated in Jones' algebra, can be stated as

$$
\begin{aligned}
\hat{K}_{C} \lambda_{K C}+\hat{K}_{D} \lambda_{K D} & =0 \\
\hat{L}_{C} \lambda_{L C}+\hat{L}_{D} \lambda_{L D} & =0
\end{aligned}
$$

Where $\lambda_{j} i$ is the share of factor $j \in K, L, Z$ invested in industry $i \in C, D$. It is again assumed that production factors are imperfect substitutes and can be substituted with elasticity of transformation $\sigma_{C}$ and $\sigma_{D}$ respectively in the clean and dirty sector. From the definition of elasticity we then have:

$$
\begin{aligned}
\hat{K}_{C}-\hat{L}_{C} & =\sigma_{C}(\hat{w}-\hat{r}) \\
\hat{K}_{D}-\hat{Z} & =\sigma_{D}\left(\hat{\tau}_{Z}-\hat{r}\right) \\
\hat{L}_{D}-\hat{Z} & =\sigma_{D}\left(\hat{\tau}_{Z}-\hat{w}\right)
\end{aligned}
$$

From the assumptions of perfect competition and free entry we have:

$$
\begin{aligned}
& \hat{P}_{C}+\hat{X}_{C}=\theta_{C K}\left(\hat{r}+\hat{K}_{C}\right)+\theta_{C L}\left(\hat{w}+\hat{L}_{C}\right) \\
& \hat{P}_{D}+\hat{X}_{D}=\theta_{D K}\left(\hat{r}+\hat{K}_{D}\right)+\theta_{D L}\left(\hat{w}+\hat{L}_{D}\right)+\theta_{D Z}\left(\hat{\tau}_{Z}+\hat{Z}\right)
\end{aligned}
$$

Where $\theta_{i} j$ is the expenditure in sector $j$ in industry $i$. From the firms cost minimization, we have that change in production of the two goods will depend from the changes in the 
production inputs, weighted by the shares of expenditure in the production factors:

$$
\begin{aligned}
& \hat{X}_{C}=\theta_{C K} \hat{K}_{C}+\theta_{C L} \hat{L}_{C} \\
& \hat{X}_{D}=\theta_{D K} \hat{K}_{D}+\theta_{D L} \hat{L}_{D}+\theta_{D Z} \hat{Z}
\end{aligned}
$$

Finally, as before utility depends on the consumption of the two goods, with an elasticity of substitution of $\sigma_{U}$ :

$$
\hat{X}_{C}-\hat{X}_{D}=\sigma_{U}\left(\hat{p}_{D}-\hat{p}_{C}\right)
$$

Setting $\hat{P}_{C}=0$ and good $X_{C}$ as the numeraire, it is possible to find the following solution to the system.

$$
\begin{aligned}
\hat{w}^{*}= & \frac{\Delta_{\Lambda} \Delta_{\sigma} \theta_{C K} \theta_{D Z} \hat{\tau}_{Z}}{D} \\
\hat{r}^{*}= & -\frac{\Delta_{\Lambda} \Delta_{\sigma} \theta_{C L} \theta_{D Z} \hat{\tau}_{Z}}{D} \\
\hat{K}_{D}^{*}= & -\frac{\Delta_{\sigma} \theta_{D Z}\left(\sigma_{C}+\Lambda_{L} \sigma_{D}\right) \hat{\tau}_{Z}}{D} \\
\hat{L}_{D}^{*}= & -\frac{\Delta_{\sigma} \theta_{D Z}\left(\sigma_{C}+\Lambda_{K} \sigma_{D}\right) \hat{\tau}_{Z}}{D} \\
\hat{K}_{C}^{*}= & \frac{\Delta_{\sigma} \theta_{D Z} \Lambda_{K}\left(\sigma_{C}+\Lambda_{L} \sigma_{D}\right) \hat{\tau}_{Z}}{D} \\
\hat{L}_{C}^{*}= & \frac{\Delta_{\sigma} \theta_{D Z} \Lambda_{L}\left(\sigma_{C}+\Lambda_{K} \sigma_{D}\right) \hat{\tau}_{Z}}{D} \\
\hat{P}_{D}^{*}= & \frac{\theta_{D Z}\left(\left(1+\theta_{C K} \Lambda_{K}+\theta_{C L} \Lambda_{L} \sigma_{C}\right)+\left(\theta_{C L} \Lambda_{K}+\left(\theta_{C K}+\Lambda_{K}\right) \Lambda_{L}\right) \sigma_{D}\right) \hat{\tau}_{Z}}{D} \\
\hat{X}_{C}^{*}= & \frac{\Delta_{\sigma} \theta_{D Z}\left(\theta_{C L} \Lambda_{L}\left(\sigma_{C}+\Lambda_{K} \sigma_{D}\right)+\theta_{C K} \Lambda_{K}\left(\sigma_{C}+\Lambda_{L} \sigma_{D}\right)\right) \hat{\tau}_{Z}}{D} \\
\hat{X}_{D}^{*}= & -\frac{\theta_{D Z}\left(\sigma_{D}\left(\left(1+\theta_{C K}\left(\Lambda_{K}-1\right)+\theta_{C L}\left(\Lambda_{L}-1\right)\right) \sigma_{C}+\Lambda_{K} \Lambda_{L}\right) \sigma_{Y}\right) \hat{\tau}_{Z}}{D} \\
& -\frac{\left(\sigma_{D}\left(\sigma_{C}+\left(\theta_{C L} \Lambda_{K}+\theta_{C K} \Lambda_{L}\right) \sigma_{D}\right)\right) \hat{\tau}_{Z}}{D}
\end{aligned}
$$




$$
\begin{aligned}
\hat{Z}^{*}= & -\frac{\left(\sigma_{D}\left(\left(1+\theta_{C K} \Lambda_{K}+\theta_{C L} \Lambda_{L}\right) \sigma_{C}+\left(\theta_{C L} \Lambda_{K}+\left(\theta_{C K}+\Lambda_{K}\right) \Lambda_{L}\right) \sigma_{D}\right)\right) \hat{\tau}_{Z}}{D} \\
& -\frac{\left(\Delta_{\sigma}\left(\Delta_{\Lambda}\left(\theta_{C L} \theta_{D K}-\theta_{C K} \theta_{D L}\right) \sigma_{D}+\theta_{D Z}\left(\sigma_{C}+\left(\theta_{C L} \Lambda_{K}+\theta_{C K} \Lambda_{L}\right) \sigma_{D}\right)\right)\right) \hat{\tau}_{Z}}{D}
\end{aligned}
$$

Where:

$$
\begin{aligned}
& \Lambda_{K}=\lambda_{K D} / \lambda_{K C} \\
& \Lambda_{L}=\lambda_{L D} / \lambda_{L C} \\
& \Delta_{\Lambda}=\Lambda_{K}-\Lambda_{L} \\
& \Delta_{\sigma}=\sigma_{U}-\sigma_{D} \\
& D=\sigma_{C}+\Lambda_{K} \Lambda_{L} \sigma_{D}+\theta_{C L}\left(\Lambda_{L} \sigma_{C}+\theta_{D K} \Delta_{\Lambda} \Delta_{\sigma}+\Lambda_{K} \sigma_{D}\right)+\theta_{C K}\left(\Lambda_{K} \sigma_{C}-\theta_{D L} \Delta_{\Lambda} \Delta_{\sigma}+\Lambda_{L} \sigma_{D}\right)
\end{aligned}
$$

For standard parameter values expression $D$ is positive. The sign of coefficients are then only dependent on $\Delta_{\sigma}$ and $\Delta_{\Lambda}$. Different conclusions can be reached from the model according to the parameter values. However, it is possible to notice that the price of the dirty good always increases, and that production of the dirty good and pollution always decrease. To check the results on the other variables it is necessary to consider the different cases of parameter values.

Case 1: $\sigma_{U}>\sigma_{D}$ and $\Lambda_{K}>\Lambda_{L}$

In this case both $\Delta_{\sigma}$ and $\Delta_{\Lambda}$ are positive, so that the quantity of both clean production factors invested will decrease in the dirty industry and increase in the clean industry. Production also increases in the clean industry. Finally, the prices of the production factors change consequently to the factor intensity. As $\Delta_{\Lambda}$, which implies that the dirty sector is more capital intensive, the price of labor will increase and the price of capital will decrease. This is because if the dirty good is more capital intensive, when price of the good increases and the the production decreases due to an environmental tax, it will demand relatively less of the production inputs $K_{D}$ and $L_{D}$, as well as less dirty input $Z$. As pro- 
duction is capital intensive, the fall in the demand for capital is greater than the fall in demand for the other clean factor $L$. Therefore, $r$ falls relatively to $w$.

Case 2: $\sigma_{U}>\sigma_{D}$ and $\Lambda_{K}<\Lambda_{L}$

In this case $\Delta_{\sigma}$ is positive and $\Delta_{\Lambda}$ is negative. The results are very similar to the first case. In fact, the only differences concern the changes in prices of the production factors. These are exactly the opposite, as production is now less capital intensive, so that the price of $K$ will increase, while the price of $L$ will decrease.

Case 3: $\sigma_{U}<\sigma_{D}$ and $\Lambda_{K}>\Lambda_{L}$

In this case $\Delta_{\sigma}$ is negative and $\Delta_{\Lambda}$ is positive. In general, the elasticity of substitution between goods in consumption is always greater than the elasticity of substitution between inputs of production in the dirty industry, thus the conclusions from cases 3 and 4 are less realistic. In this case the conclusions are opposite to case 1 . The quantity of both clean production factors invested will increase in the dirty industry and decrease in the clean industry. Production decreases in the clean industry, the price of $K$ increases and the price of $L$ decreases.

Case 4: $\sigma_{U}<\sigma_{D}$ and $\Lambda_{K}<\Lambda_{L}$

In this case both $\Delta_{\sigma}$ and $\Delta_{\Lambda}$ are negative. The results are very similar to case 3, except that the price of $K$ decreases, while the price of $L$ increases.

Note that the results are the same as in the version of the model without labor, only more complicated. Here the relative intensity of production factors can lead to different changes in the factor prices.

This model is easily modified to the case in which capital is imperfectly malleable. In this case, we have $\hat{K}_{C}=\hat{K}_{D}=0$ and two different prices for the two types of capital, $\hat{r}_{C}$ 
and $\hat{r}_{D}$. This affects the following equations which become:

$$
\begin{aligned}
\hat{L}_{C} & =-\sigma_{C}\left(\hat{w}-\hat{r}_{C}\right) \\
\hat{Z} & =-\sigma_{D}\left(\hat{\tau}_{Z}-\hat{r}\right) \\
\hat{X}_{C} & =\theta_{C K} \hat{r}_{C}+\theta_{C L}\left(\hat{w}+\hat{L}_{C}\right) \\
\hat{P}_{D}+\hat{X}_{D} & =\theta_{D K} \hat{r}+\theta_{D L}\left(\hat{w}+\hat{L}_{D}\right)+\theta_{D Z}\left(\hat{\tau}_{Z}+\hat{Z}\right)
\end{aligned}
$$

The new system of equations gives the following results:

$$
\begin{aligned}
\hat{w}^{*} & =-\frac{\Delta_{\sigma} \theta_{C K} \theta_{D Z} \Lambda_{L} \sigma_{D} \hat{\tau}_{Z}}{D} \\
\hat{r}_{C}^{*} & =\frac{\Delta_{\sigma} \theta_{C L} \theta_{D Z} \Lambda_{L} \sigma_{D} \hat{\tau}_{Z}}{D} \\
\hat{r}_{D}^{*} & =-\frac{\Delta_{\sigma} \theta_{D Z}\left(\sigma_{C}+\theta_{C K} \Lambda_{L} \sigma_{D}\right) \hat{\tau}_{Z}}{D} \\
\hat{L}_{C}^{*} & =\frac{\Delta_{\sigma} \theta_{D Z} \Lambda_{L} \sigma_{C} \sigma_{D} \hat{\tau}_{Z}}{D} \\
\hat{L}_{D}^{*} & =-\frac{\Delta_{\sigma} \theta_{D Z} \sigma_{C} \sigma_{D} \hat{\tau}_{Z}}{D} \\
\hat{P}_{D}^{*} & =\frac{\theta_{D Z} \sigma_{D}\left(\left(1+\theta_{C L} \Lambda_{L}\right) \sigma_{C}+\theta_{C K} \Lambda_{L} \sigma_{D}\right) \hat{\tau}_{Z}}{D} \\
\hat{X}_{C}^{*} & =\frac{\Delta_{\sigma} \theta_{C L} \theta_{D Z} \Lambda_{L} \sigma_{C} \sigma_{D} \hat{\tau}_{Z}}{D} \\
\hat{X}_{D}^{*} & =-\frac{\theta_{D Z} \sigma_{D}\left(\sigma_{U} \sigma_{C}+\Lambda_{L}\left(\theta_{C K} \sigma_{U}+\theta_{C L} \sigma_{C}\right) \sigma_{D}\right) \hat{\tau}_{Z}}{D} \\
\hat{Z}^{*} & =-\sigma_{D}\left(D+\frac{\Delta_{\sigma} \theta_{C K} \theta_{D Z} \Lambda_{L} \sigma_{D}}{D}\right) \hat{\tau}_{Z}
\end{aligned}
$$

Where:

$$
\begin{aligned}
\Delta_{\sigma} & =\sigma_{U}-\sigma_{D} \\
D & =\theta_{D K} \sigma_{U} \sigma_{C}+\left(\theta_{C K}\left(\theta_{D K}+\theta_{D L}\right) \Lambda_{L} \sigma_{U}+\left(\theta_{D L}+\theta_{D Z}+\theta_{C K} \Lambda_{L}\right) \sigma_{C}\right) \sigma_{D}+\theta_{C K} \theta_{D Z} \Lambda_{L} \sigma_{D}^{2}
\end{aligned}
$$

As before results depend on parameter values, but this time only on whether $\sigma_{U}$ is greater than $\sigma_{D}$. In either case, pollution decreases, the price of the dirty good increases 
and production in the dirty sector decreases. If $\sigma_{U}>\sigma_{D}$, production and use of inputs in the clean sector increase and the price of $L$ decreases. The prices of capital change in an opposite way in the two sectors. In the dirty sector, production decreases and less capital is demanded, so that the price of capital decreases. In the clean sector, production increases, so that more capital is demanded and the price of the clean capital increases. These are the expected conclusions from the model, and the ones related to the more realistic parameter values. If $\sigma_{U}<\sigma_{D}$, conclusions are the opposite for what concerns production in the clean sector, use of $L$ and changes in the prices of the production inputs.

A numerical analysis is performed and parameters for several regions and countries are calculated from the GTAP database and reported in Table 5.

Comparing the values in Table 5 with those used by Fullerton and Heutel [12], which are based on stylized facts and on the US economy ${ }^{15}$, it is possible to see that they indicate a very similar production structure. As in Fullerton Heutel [12], the values of the $\lambda^{\prime} \mathrm{s}$ show that the clean sector is bigger than the dirty one and that the clean inputs constitute the biggest share. The share of labor is the biggest in the dirty sector. For most countries capital is the second biggest input in the production of the dirty good. However, for some countries $\theta_{D Z}$ is smaller than $\theta_{D K}$, showing that the dirty inputs can be a very small share in production even in the dirty industry. Despite differing from the general values used by Fullerton and Heutel [12], this is still plausible as the countries with these characteristics are mostly developing countries and transition economies such as the former Soviet Union area, in which energy inputs constitute a bigger share in the production of energy-intensive products.

For what regards the elasticities of substitution, it is not possible to obtain them from the GTAP database, thus it is necessary to make assumptions on them. Following Fuller-

\footnotetext{
${ }^{15}$ Fullerton and Heutel [12] assume that the share of labor and capital invested in the clean industry is 0.8 $\left(\lambda_{L C}=\lambda_{L D}=.8\right)$, that the input share of capital in the clean industry $\left(\theta_{K C}\right)$ is .4, and that the the inputs to the dirty industry contribute to production with shares $\theta_{K D}=.3, \theta_{L D}=.45$ and $\theta_{Z D}=.25$.
} 
ton and Metcalf [13], a unity substitution elasticity in consumption between the clean and dirty good $\left(\sigma_{U}=1\right)$ is assumed. The elasticity of substitution between inputs in the clean industry is set to .7 instead $\left(\sigma_{C}=.7\right)$, as in Pessoa et al. $[26]^{16}$. In the calculations the value of the tax increase is $10 \%$, as in Fullerton and Heutel [12]. This is an arbitrary value used to study the different conclusions the two models reach.

Table 5 illustrates results for the numerical analysis of the model with perfect capital malleability. Results reflect the predictions of the theoretical model for the case in which $\sigma_{U}>\sigma_{D}$. As expected, production of the clean good increases, while that of the dirty good decreases. There is also an adjustment in the use of production factors in both industries. In fact, capital investments decrease in the dirty industry and move towards the clean industry. As production of the clean good grows, labor invested to produce it also increases, while decreasing in the dirty industry. Pollution $Z$ also decreases as a consequence of the environmental tax imposed. These results apply to all countries and regions considered.

Results on the prices of the production factors instead vary between regions, as they depend on the relative factor intensities. In some regions the price of capital increases while the price of the other production factor decreases. Whereas in other regions the opposite situation is verified. This is because prices change according to the initial intensity of use of the input resources. In countries in which production is more capital intensive, that is $K_{D} / K_{C}>L_{D} / L_{C}$, as capital becomes more demanded it also becomes more expensive. Thus, the price of capital $r$ grows. On the other hand, where production is less capital intensive, that is $K_{D} / K_{C}<L_{D} / L_{C}$, the price of capital decreases, while the price of $L, w$ increases. Note how there are only a few countries that are relatively more capital intensive ${ }^{17}$. These are the NAFTA regions, Scandinavian countries, Switzerland, Czech

\footnotetext{
${ }^{16}$ Fullerton and Heutel [12] assume a unity elasticity of substitution between capital and labor, based on estimates obtained by Lovell [23] and Corbo and Meller [8]. More recent estimates, such as by Pessoa et al. [26] and Collins and Williams [7] support a value of .7. Furthermore, these estimate are more relevant to the present work as they are based on OECD data rather than US data, as the previous studies.

${ }^{17}$ This is also due to the fact that the production factor $L$ includes different production factors, and is therefore a big share of the inputs
} 
Republic, the Netherlands and Portugal.

Results on the reduction in pollution are similar to those obtained by Fullerton and Heutel [12]. They find that a $10 \%$ increase in the tax yields to approximately a $6 \%$ increase in pollution. In the calculations in table 5 , pollution changes range from -7.5 in Russia to -5.1 in Switzerland.

Welfare changes once again depend on $\hat{Z}$, so that they will be higher the greater the change in pollution. Thus, welfare improves more in the case of perfect malleability of capital.

Table 7 shows that results in the case of imperfect capital malleability follow the same pattern in all countries. As in the previous case, more of the production factor $L$ is used in the clean industry, and less in the dirty industry, production increases in the clean industry and decreases in the dirty industry, pollution decreases and the price of the dirty good increases. Unlike the previous case however, the price of $L$ always decreases. This is because $L$ becomes relatively less scarce compared with the other production factors, and therefore it loses value. In the clean industry the price of capital increases. This is because, as production increases, more capital is demanded. The opposite happens in the dirty industry, where, as production decreases, capital becomes less demanded and thus less expensive. Welfare is also negatively affected by the carbon tax, even though less than in the case of perfect capital malleability.

By comparing the results, it is possible to see that the carbon tax has a higher effect in the case of perfect capital malleability. In fact, in this case there is a more effective re-adjustment of production patterns and a higher reduction of pollution. Welfare is also more affected in the case of capital malleability, as it is more expensive to offset the costs of the tax and of a higher pollution reduction. Although results are now dependent on relative factor intensities, the overall conclusions of the model are the same as the ones with a single production factor $K$. 


\section{Tables and Figures}

Figure 1: $\hat{X}_{D}$ and $\hat{Z}$ contours

\section{A. $\hat{X}_{D}$ Contours}
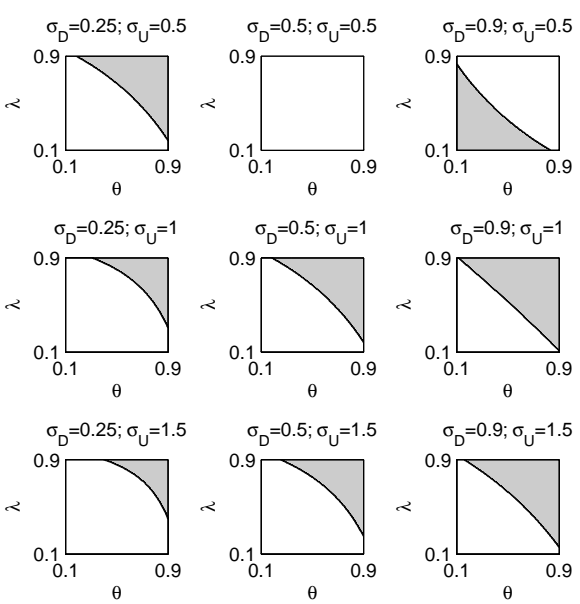

White: $\hat{X}_{D}$ larger w/. malleable capital Gray: $\hat{X}_{D}$ larger $w /$. fixed capital
B. $\hat{Z}$ Contours
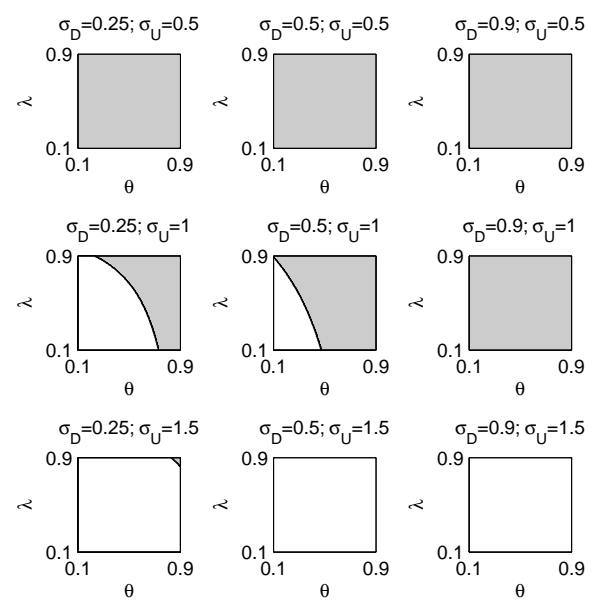

White: $\hat{Z}$ larger w/. malleable capital Gray: $\hat{Z}$ larger w/. fixed capital 
Figure 2: Parameter values $-\theta$ and $\lambda$

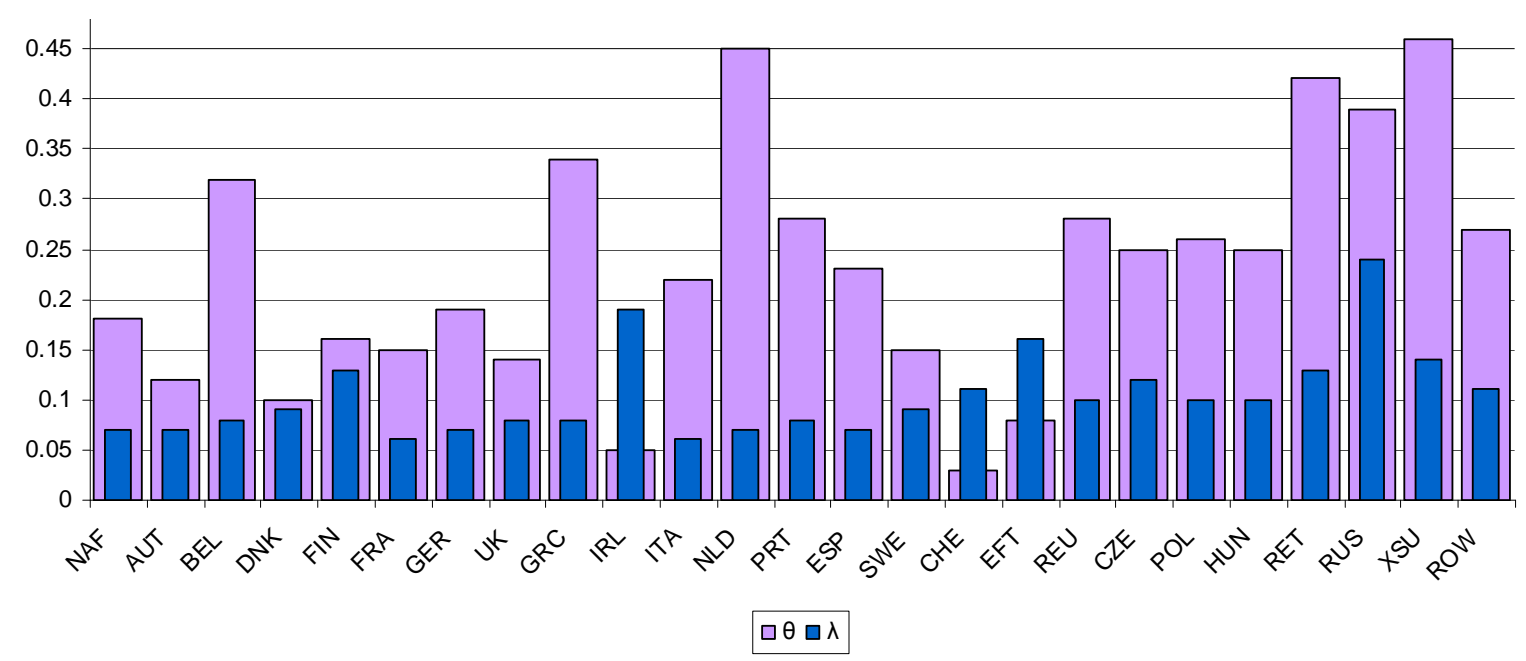

Figure 3: Parameter values $-\theta$ and $\lambda$
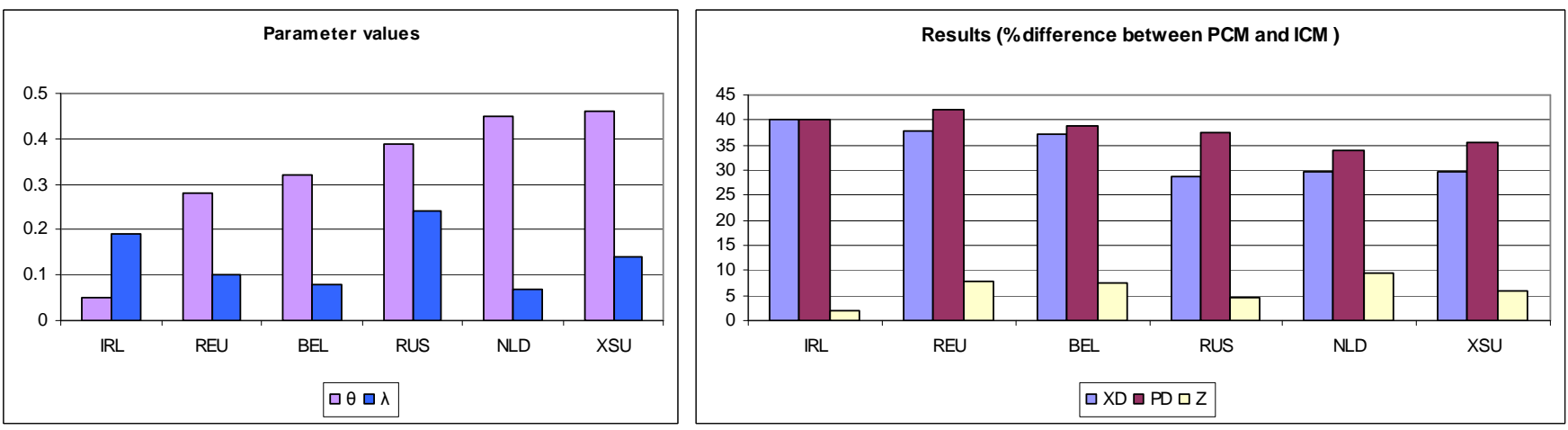
Figure 4: Production Tree

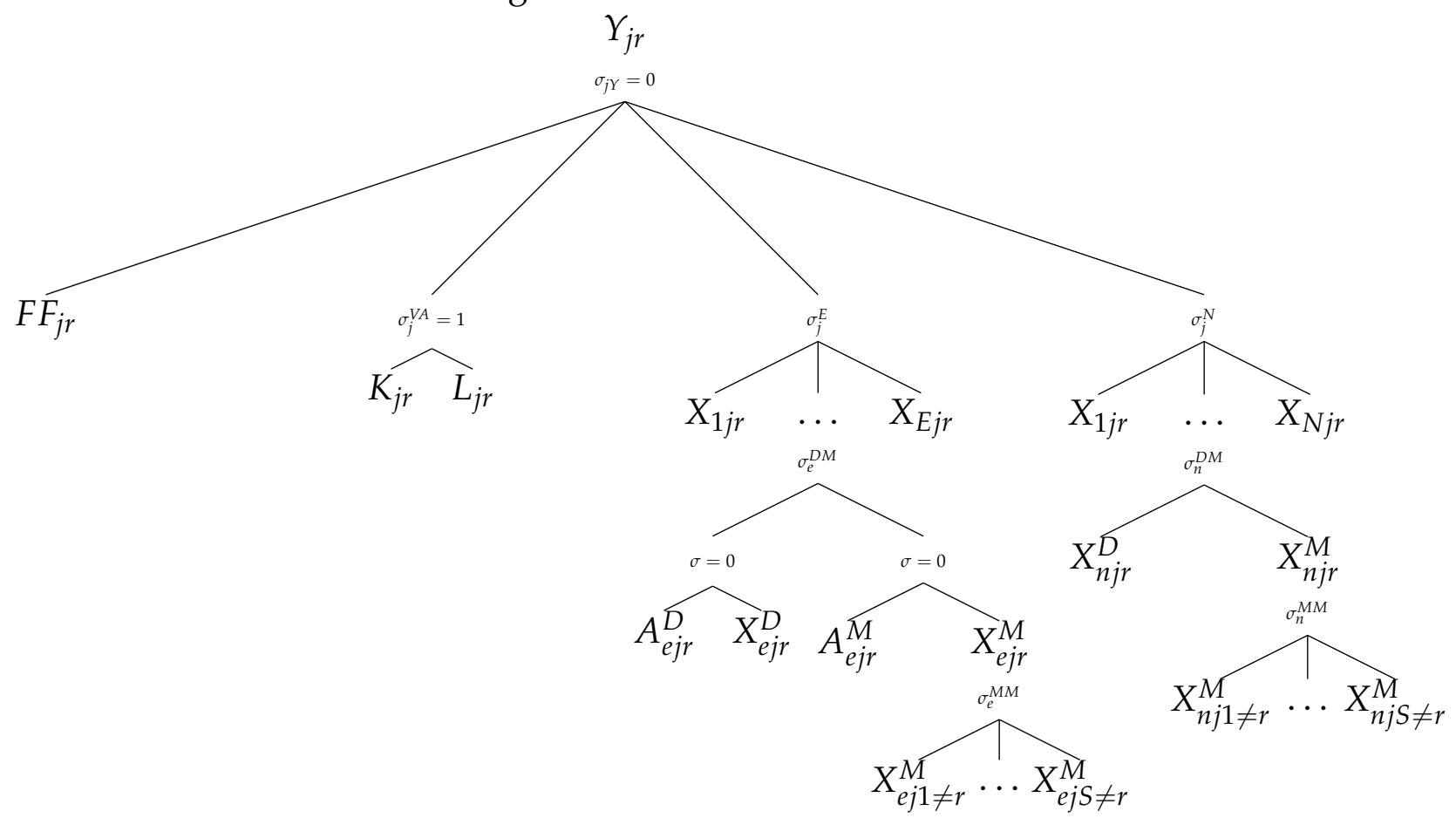

Table 1: Results of the Theoretical Model

\begin{tabular}{lcc}
\hline Variable & A. Malleable Capital & B. Non-Malleable Capital \\
\hline$\hat{P}_{C}$ & 0 & 0 \\
$\hat{P}_{D}$ & $\theta \hat{\tau}_{Z}$ & $\frac{\theta \sigma_{D}}{\left(\theta \sigma_{D}+(1-\theta) \sigma_{U}\right)} \hat{\tau}_{Z}$ \\
$\hat{r}_{,} \hat{r}_{D}, \hat{r}_{C}$ & $\hat{r}=0$ & $\hat{r}_{D}=-\frac{\theta\left(\sigma_{U}-\sigma_{D}\right)}{\left(\theta \sigma_{D}+(1-\theta) \sigma_{U}\right)} \hat{\tau}_{Z}, \hat{r}_{C}=0$ \\
$\hat{X}_{C}$ & $\theta \lambda\left(\sigma_{U}-\sigma_{D}\right) \hat{\tau}_{Z}$ & 0 \\
$\hat{X}_{D}$ & $-\theta\left(\lambda \sigma_{D}+(1-\lambda) \sigma_{U}\right) \hat{\tau}_{Z}$ & $\theta \sigma_{D} \sigma_{U}$ \\
$\hat{K}_{C}$ & $\theta \lambda\left(\sigma_{U}-\sigma_{D}\right) \hat{\tau}_{Z}$ & 0 \\
$\hat{K}_{D}$ & $-\theta(1-\lambda)\left(\sigma_{U}-\sigma_{D}\right) \hat{\tau}_{Z}$ & 0 \\
$\hat{Z}$ & $-\left[\theta(1-\lambda) \sigma_{U}+(1-\theta(1-\lambda)) \sigma_{D}\right] \hat{\tau}_{Z}$ & \\
$\hat{W}$ & $\hat{\tau}_{Z}\left\{\delta \zeta \sigma_{D}+\theta\left(\sigma_{U}-\sigma_{D}\right)\right.$ & $\frac{\sigma_{D} \sigma_{U}}{\left(\theta \sigma_{D}+(1-\theta) \sigma_{U}\right)} \hat{\tau}_{Z}$ \\
& $\times[\lambda(1-\phi)+(\delta \zeta-\phi)(1-\lambda)]\}$ & $\frac{\sigma_{D} \sigma_{U}(\delta \zeta-\theta \phi)}{\left(\theta \sigma_{D}+(1-\theta) \sigma_{U}\right)} \hat{\tau}_{Z}$ \\
\hline
\end{tabular}


Table 2: Results from Numerical Analysis ( ${ }^{*}$ Perfect, ${ }^{* *}$ Imperfect Capital Malleability)

\begin{tabular}{|c|c|c|c|c|c|c|c|c|c|c|c|c|c|c|c|}
\hline \multirow{2}{*}{ REG } & \multirow{2}{*}{$\theta$} & \multirow{2}{*}{$\lambda$} & \multirow{2}{*}{$\phi$} & \multicolumn{7}{|c|}{ PCM $^{*}$} & \multicolumn{5}{|c|}{$\mathbf{I C M}^{* *}$} \\
\hline & & & & $\hat{K}_{D}$ & $\hat{K}_{C}$ & $\hat{X}_{D}$ & $\hat{X}_{C}$ & $\hat{P}_{D}$ & $\bar{Z}$ & $\hat{W}$ & $\hat{r}_{D}$ & $\tilde{X}_{D}$ & $\hat{P}_{D}$ & $\hat{Z}$ & $\hat{W}$ \\
\hline NAF & 0.18 & 0.07 & 0.04 & -0.9 & 0.1 & -1.9 & 0.1 & 1.9 & -5.9 & 1.6 & 1.1 & -1.1 & 1.1 & -5.5 & -4.6 \\
\hline AUT & 0.12 & 0.07 & 0.02 & -0.7 & 0.1 & -1.5 & 0.1 & 1.5 & -5.7 & 6.3 & 0.8 & -0.8 & 0.8 & -5.4 & -1.9 \\
\hline BEL & 0.32 & 0.08 & 0.03 & -1.6 & 0.2 & -3.5 & 0.2 & 3.6 & -6.6 & 8.3 & 2.2 & -2.2 & 2.2 & -6.1 & -7.0 \\
\hline DNK & 0.1 & 0.09 & 0.03 & -0.5 & 0.0 & -1.0 & 0.0 & 1.0 & -5.5 & -3.4 & 0.5 & -0.5 & 0.5 & -5.3 & -1.7 \\
\hline FIN & 0.16 & 0.13 & 0.05 & -0.7 & 0.1 & -1.5 & 0.1 & 1.6 & -5.7 & 2.6 & 0.9 & -0.9 & 0.9 & -5.4 & -4.2 \\
\hline FRA & 0.15 & 0.06 & 0.06 & -0.9 & 0.1 & -1.9 & 0.1 & 1.9 & -5.9 & -1.8 & 1.1 & -1.1 & 1.1 & -5.5 & -6.5 \\
\hline GER & 0.19 & 0.07 & 0.04 & -1.0 & 0.1 & -2.2 & 0.1 & 2.3 & -6.0 & 1.3 & 1.3 & -1.3 & 1.3 & -5.6 & -4.9 \\
\hline UK & 0.14 & 0.08 & 0.03 & -0.7 & 0.1 & -1.4 & 0.1 & 1.5 & -5.7 & 4.8 & 0.8 & -0.8 & 0.8 & -5.4 & -2.8 \\
\hline GRC & 0.34 & 0.08 & 0.05 & -1.6 & 0.1 & -3.3 & 0.1 & 3.4 & -6.6 & -6.5 & 2.1 & -2.1 & 2.1 & -6.0 & -10.2 \\
\hline IRL & 0.05 & 0.19 & 0.04 & -0.2 & 0.1 & -0.5 & 0.1 & 0.5 & -5.2 & 7.8 & 0.3 & -0.3 & 0.3 & -5.1 & -1.1 \\
\hline ITA & 0.22 & 0.06 & 0.06 & -1.2 & 0.1 & -2.4 & 0.1 & 2.5 & -6.2 & -3.8 & 1.4 & -1.4 & 1.4 & -5.7 & -7.7 \\
\hline NLD & 0.45 & 0.07 & 0.04 & -2.3 & 0.2 & -4.7 & 0.2 & 5.0 & -7.3 & -0.3 & 3.3 & -3.3 & 3.3 & -6.6 & -13.7 \\
\hline PRT & 0.28 & 0.08 & 0.06 & -1.4 & 0.1 & -2.9 & 0.1 & 3.0 & -6.4 & -6.8 & 1.8 & -1.8 & 1.8 & -5.9 & -10.1 \\
\hline ESP & 0.23 & 0.07 & 0.04 & -1.2 & 0.1 & -2.5 & 0.1 & 2.6 & -6.2 & 0.6 & 1.5 & -1.5 & 1.5 & -5.7 & -5.5 \\
\hline SWE & 0.15 & 0.09 & 0.04 & -0.8 & 0.1 & -1.6 & 0.1 & 1.7 & -5.8 & 3.1 & 1.0 & -1.0 & 1.0 & -5.5 & -4.1 \\
\hline CHE & 0.03 & 0.11 & 0.02 & -0.1 & 0.0 & -0.3 & 0.0 & 0.3 & -5.1 & -0.7 & 0.2 & -0.2 & 0.2 & -5.1 & -0.5 \\
\hline EFT & 0.08 & 0.16 & 0.03 & -0.4 & 0.1 & -0.8 & 0.1 & 0.9 & -5.4 & 7.2 & 0.5 & -0.5 & 0.5 & -5.2 & -1.6 \\
\hline REU & 0.28 & 0.1 & 0.04 & -1.4 & 0.2 & -2.9 & 0.2 & 3.1 & -6.4 & 8.0 & 1.8 & -1.8 & 1.8 & -5.9 & -7.0 \\
\hline CZE & 0.25 & 0.12 & 0.05 & -1.2 & 0.2 & -2.6 & 0.2 & 2.8 & -6.2 & 5.1 & 1.6 & -1.6 & 1.6 & -5.8 & -8.5 \\
\hline POL & 0.26 & 0.1 & 0.06 & -1.3 & 0.2 & -2.8 & 0.2 & 3.0 & -6.3 & 2.7 & 1.8 & -1.8 & 1.8 & -5.9 & -10.4 \\
\hline HUN & 0.25 & 0.1 & 0.05 & -1.2 & 0.2 & -2.6 & 0.2 & 2.8 & -6.2 & 4.6 & 1.6 & -1.6 & 1.6 & -5.8 & -8.8 \\
\hline RET & 0.42 & 0.13 & 0.06 & -1.9 & 0.3 & -4.0 & 0.3 & 4.3 & -6.9 & 5.1 & 2.7 & -2.7 & 2.7 & -6.4 & -15.6 \\
\hline RUS & 0.39 & 0.24 & 0.08 & -1.5 & 0.5 & -3.5 & 0.5 & 4.0 & -6.5 & 18.4 & 2.5 & -2.5 & 2.5 & -6.2 & -19.8 \\
\hline XSU & 0.46 & 0.14 & 0.11 & -2.0 & 0.4 & -4.4 & 0.4 & 4.8 & -7.0 & -10.6 & 3.1 & -3.1 & 3.1 & -6.6 & -32.7 \\
\hline ROW & 0.27 & 0.11 & 0.04 & -1.2 & 0.2 & -2.6 & 0.2 & 2.8 & -6.2 & 8.2 & 1.6 & -1.6 & 1.6 & -5.8 & -6.8 \\
\hline
\end{tabular}


Table 3: Emission Results from Simulations - Mtoe $\mathrm{CO}_{2}$

\begin{tabular}{|l|c|c|c|c|c|c|}
\hline \multirow{2}{*}{ REG } & \multicolumn{2}{|c|}{ Baseline } & \multicolumn{2}{c|}{ ETS - PCM } & \multicolumn{2}{c|}{ ETS - ICM } \\
\cline { 2 - 7 } & Cov & NCov & Cov & NCov & Cov & NCov \\
\hline NAF & 3572.6 & 3114.1 & 3605.2 & 3130.6 & 3630.9 & 3046.6 \\
AUT & 36.1 & 41.0 & 32.7 & 39.8 & 31.8 & 39.0 \\
BEL & 97.9 & 93.8 & 75.6 & 84.5 & 75.0 & 80.6 \\
DNK & 24.0 & 24.0 & 21.1 & 23.8 & 21.2 & 22.8 \\
FIN & 115.4 & 26.9 & 59.4 & 24.9 & 55.9 & 24.4 \\
FRA & 116.6 & 340.1 & 106.1 & 332.0 & 105.0 & 329.5 \\
GER & 516.9 & 426.4 & 439.9 & 401.8 & 443.5 & 397.5 \\
UK & 309.5 & 237.2 & 271.1 & 228.2 & 267.8 & 222.5 \\
GRC & 85.1 & 45.9 & 67.7 & 43.6 & 69.1 & 42.7 \\
IRL & 23.6 & 33.5 & 20.7 & 32.7 & 20.7 & 32.1 \\
ITA & 219.6 & 198.8 & 195.4 & 192.3 & 193.8 & 187.9 \\
NLD & 255.8 & 72.5 & 165.6 & 61.5 & 172.7 & 63.9 \\
PRT & 30.3 & 31.1 & 26.9 & 30.3 & 26.5 & 29.4 \\
ESP & 183.0 & 197.9 & 159.2 & 191.7 & 159.0 & 188.7 \\
SWE & 26.4 & 44.6 & 24.4 & 43.5 & 24.1 & 42.7 \\
CHE & 4.8 & 46.5 & 4.8 & 44.0 & 4.4 & 40.6 \\
EFT & 20.4 & 43.4 & 21.5 & 43.6 & 21.8 & 43.3 \\
REU & 104.2 & 79.1 & 88.9 & 80.0 & 88.4 & 79.3 \\
CZE & 111.7 & 45.2 & 85.3 & 43.6 & 87.4 & 44.1 \\
POL & 262.5 & 124.1 & 211.1 & 124.2 & 210.5 & 122.5 \\
HUN & 38.7 & 42.9 & 31.6 & 42.8 & 30.3 & 39.4 \\
RET & 216.0 & 112.3 & 221.1 & 113.2 & 220.8 & 110.8 \\
RUS & 1205.2 & 688.6 & 1224.7 & 691.2 & 1249.7 & 686.6 \\
XSU & 562.2 & 409.9 & 574.8 & 414.8 & 523.6 & 373.6 \\
ROW & 12083.8 & 9316.3 & 12298.5 & 9415.3 & 12515.4 & 9362.7 \\
\hline EU & 2557.4 & 2105.0 & 2082.6 & 2021.0 & 2082.7 & 1989.1 \\
Non-EU & 17664.9 & 13731.0 & 17950.6 & 13852.7 & 18166.5 & 13664.2 \\
TOT & 20222.3 & 15836.0 & 20033.2 & 15873.7 & 20249.3 & 15653.4 \\
\hline
\end{tabular}


Table 4: ETS results

\begin{tabular}{|l|c|c|c|}
\hline & & $\begin{array}{c}\text { Emissions PCM } \\
\text { (Price=23.23€) }\end{array}$ & $\begin{array}{c}\text { Emissions ICM } \\
\text { (Price=24.45€) }\end{array}$ \\
\hline AUT & 31 & 33 & 32 \\
BEL & 59 & 76 & 75 \\
DNK & 25 & 21 & 21 \\
FIN & 38 & 59 & 56 \\
FRA & 133 & 106 & 105 \\
GER & 453 & 440 & 444 \\
UK & 246 & 271 & 268 \\
GRC & 69 & 68 & 69 \\
IRL & 22 & 21 & 21 \\
ITA & 196 & 195 & 194 \\
NLD & 86 & 166 & 173 \\
PRT & 35 & 27 & 26 \\
ESP & 152 & 159 & 159 \\
SWE & 23 & 24 & 24 \\
REU & 194 & 89 & 88 \\
CZE & 87 & 85 & 87 \\
POL & 209 & 211 & 210 \\
HUN & 27 & 32 & 30 \\
\hline
\end{tabular}


Table 5: Region-specific Parameters

\begin{tabular}{|l|c|c|c|c|c|c|c|c|c|}
\hline REG & $\theta_{D Z}$ & $\theta_{D K}$ & $\theta_{D L}$ & $\theta_{C K}$ & $\theta_{C L}$ & $\lambda_{K C}$ & $\lambda_{K D}$ & $\lambda_{L C}$ & $\lambda_{L D}$ \\
\hline NAF & 0.17 & 0.20 & 0.63 & 0.21 & 0.79 & 0.94 & 0.06 & 0.95 & 0.05 \\
AUT & 0.08 & 0.17 & 0.75 & 0.25 & 0.75 & 0.94 & 0.06 & 0.92 & 0.08 \\
BEL & 0.23 & 0.10 & 0.67 & 0.17 & 0.83 & 0.95 & 0.05 & 0.93 & 0.07 \\
DNK & 0.10 & 0.16 & 0.74 & 0.17 & 0.83 & 0.94 & 0.06 & 0.94 & 0.06 \\
FIN & 0.09 & 0.20 & 0.72 & 0.20 & 0.80 & 0.85 & 0.15 & 0.86 & 0.14 \\
FRA & 0.10 & 0.19 & 0.72 & 0.25 & 0.75 & 0.94 & 0.06 & 0.93 & 0.07 \\
GER & 0.12 & 0.14 & 0.74 & 0.21 & 0.79 & 0.95 & 0.05 & 0.93 & 0.07 \\
UK & 0.12 & 0.14 & 0.73 & 0.18 & 0.82 & 0.95 & 0.05 & 0.94 & 0.06 \\
GRC & 0.28 & 0.10 & 0.61 & 0.18 & 0.82 & 0.96 & 0.04 & 0.95 & 0.05 \\
IRL & 0.12 & 0.13 & 0.75 & 0.19 & 0.81 & 0.97 & 0.03 & 0.96 & 0.04 \\
ITA & 0.15 & 0.15 & 0.70 & 0.28 & 0.72 & 0.96 & 0.04 & 0.92 & 0.08 \\
NLD & 0.36 & 0.14 & 0.49 & 0.19 & 0.81 & 0.94 & 0.06 & 0.95 & 0.05 \\
PRT & 0.16 & 0.13 & 0.71 & 0.12 & 0.88 & 0.91 & 0.09 & 0.94 & 0.06 \\
ESP & 0.16 & 0.20 & 0.64 & 0.24 & 0.76 & 0.94 & 0.06 & 0.93 & 0.07 \\
SWE & 0.08 & 0.15 & 0.77 & 0.14 & 0.86 & 0.89 & 0.11 & 0.91 & 0.09 \\
CHE & 0.03 & 0.18 & 0.79 & 0.19 & 0.81 & 0.93 & 0.07 & 0.93 & 0.07 \\
EFT & 0.10 & 0.17 & 0.73 & 0.22 & 0.78 & 0.94 & 0.06 & 0.93 & 0.07 \\
REU & 0.17 & 0.12 & 0.71 & 0.19 & 0.81 & 0.92 & 0.08 & 0.89 & 0.11 \\
CZE & 0.14 & 0.16 & 0.70 & 0.17 & 0.83 & 0.89 & 0.11 & 0.90 & 0.10 \\
POL & 0.19 & 0.15 & 0.66 & 0.21 & 0.79 & 0.93 & 0.07 & 0.92 & 0.08 \\
HUN & 0.21 & 0.14 & 0.65 & 0.21 & 0.79 & 0.94 & 0.06 & 0.93 & 0.07 \\
RET & 0.18 & 0.09 & 0.74 & 0.13 & 0.87 & 0.91 & 0.09 & 0.88 & 0.12 \\
RUS & 0.55 & 0.06 & 0.39 & 0.22 & 0.78 & 0.95 & 0.05 & 0.91 & 0.09 \\
XSU & 0.15 & 0.04 & 0.81 & 0.06 & 0.94 & 0.89 & 0.11 & 0.85 & 0.15 \\
ROW & 0.19 & 0.17 & 0.63 & 0.21 & 0.79 & 0.92 & 0.08 & 0.92 & 0.08 \\
\hline
\end{tabular}


Table 6: Results with Perfect Malleability of Capital

\begin{tabular}{|l|c|c|c|c|c|c|c|c|c|c|}
\hline REG & $\hat{w}$ & $\hat{r}$ & $\hat{K}_{C}$ & $\hat{K}_{D}$ & $\hat{L}_{C}$ & $\hat{L}_{D}$ & $\hat{X}_{C}$ & $\hat{X}_{D}$ & $\hat{P}_{D}$ & $\hat{Z}$ \\
\hline NAF & 0.0 & 0.0 & -0.1 & -0.8 & 0.0 & -0.8 & 0.0 & -0.2 & 2.4 & -5.8 \\
AUT & 0.0 & 0.0 & 0.0 & -0.4 & 0.0 & -0.4 & 0.0 & -0.2 & 1.1 & -5.4 \\
BEL & 0.0 & 0.0 & -0.1 & -1.1 & -0.1 & -1.1 & 0.1 & -0.2 & 3.2 & -6.1 \\
DNK & 0.0 & 0.0 & 0.0 & -0.5 & 0.0 & -0.5 & 0.0 & -0.2 & 1.4 & -5.5 \\
FIN & 0.0 & 0.0 & -0.1 & -0.4 & -0.1 & -0.4 & 0.1 & -0.4 & 1.2 & -5.4 \\
FRA & 0.0 & 0.0 & 0.0 & -0.5 & 0.0 & -0.5 & 0.0 & -0.2 & 1.4 & -5.5 \\
GER & 0.0 & 0.0 & 0.0 & -0.6 & 0.0 & -0.6 & 0.0 & -0.2 & 1.7 & -5.6 \\
UK & 0.0 & 0.0 & 0.0 & -0.6 & 0.0 & -0.6 & 0.0 & -0.1 & 1.7 & -5.6 \\
GRC & 0.0 & 0.0 & -0.1 & -1.3 & -0.1 & -1.3 & 0.1 & -0.1 & 3.9 & -6.3 \\
IRL & 0.0 & 0.0 & 0.0 & -0.6 & 0.0 & -0.6 & 0.0 & -0.1 & 1.7 & -5.6 \\
ITA & 0.0 & 0.0 & 0.0 & -0.7 & -0.1 & -0.7 & 0.1 & -0.2 & 2.1 & -5.7 \\
NLD & 0.0 & 0.0 & -0.1 & -1.7 & -0.1 & -1.7 & 0.1 & -0.2 & 5.0 & -6.7 \\
PRT & 0.0 & 0.0 & -0.1 & -0.7 & -0.1 & -0.8 & 0.1 & -0.2 & 2.2 & -5.7 \\
ESP & 0.0 & 0.0 & -0.1 & -0.8 & -0.1 & -0.7 & 0.1 & -0.2 & 2.2 & -5.7 \\
SWE & 0.0 & 0.0 & 0.0 & -0.4 & 0.0 & -0.4 & 0.0 & -0.3 & 1.1 & -5.4 \\
CHE & 0.0 & 0.0 & 0.0 & -0.1 & 0.0 & -0.1 & 0.0 & -0.2 & 0.4 & -5.1 \\
EFT & 0.0 & 0.0 & 0.0 & -0.5 & 0.0 & -0.5 & 0.0 & -0.2 & 1.4 & -5.5 \\
REU & 0.0 & 0.0 & -0.1 & -0.8 & -0.1 & -0.8 & 0.1 & -0.3 & 2.3 & -5.8 \\
CZE & 0.0 & 0.0 & -0.1 & -0.6 & -0.1 & -0.6 & 0.1 & -0.3 & 1.9 & -5.6 \\
POL & 0.0 & 0.0 & -0.1 & -0.9 & -0.1 & -0.9 & 0.1 & -0.2 & 2.6 & -5.9 \\
HUN & 0.0 & 0.0 & -0.1 & -1.0 & -0.1 & -1.0 & 0.1 & -0.2 & 2.9 & -6.0 \\
RET & 0.0 & 0.0 & -0.1 & -0.8 & -0.1 & -0.8 & 0.1 & -0.3 & 2.4 & -5.8 \\
RUS & 0.0 & 0.1 & -0.1 & -2.6 & -0.3 & -2.5 & 0.2 & -0.3 & 7.6 & -7.5 \\
XSU & 0.0 & 0.0 & -0.1 & -0.7 & -0.1 & -0.6 & 0.1 & -0.3 & 2.0 & -5.6 \\
ROW & 0.0 & 0.0 & -0.1 & -0.9 & -0.1 & -0.9 & 0.1 & -0.2 & 2.6 & -5.9 \\
\hline
\end{tabular}


Table 7: Results with Imperfect Malleability of Capital

\begin{tabular}{|l|c|c|c|c|c|c|c|c|c|}
\hline REG & $\hat{w}$ & $\hat{r}_{C}$ & $\hat{r}_{D}$ & $\hat{L}_{C}$ & $\hat{L}_{D}$ & $\hat{X}_{C}$ & $\hat{X}_{D}$ & $\hat{P}_{D}$ & $\hat{Z}$ \\
\hline NAF & 0.0 & 0.0 & -1.5 & 0.0 & -0.7 & 0.0 & -13.8 & 14.4 & -5.7 \\
AUT & 0.0 & 0.0 & -0.8 & 0.0 & -0.4 & 0.0 & -7.7 & 8.5 & -5.4 \\
BEL & 0.0 & 0.1 & -1.7 & 0.1 & -0.8 & 0.0 & -10.8 & 11.7 & -5.8 \\
DNK & 0.0 & 0.0 & -1.0 & 0.0 & -0.5 & 0.0 & -9.9 & 10.5 & -5.5 \\
FIN & 0.0 & 0.1 & -0.9 & 0.1 & -0.4 & 0.0 & -4.0 & 4.6 & -5.4 \\
FRA & 0.0 & 0.0 & -1.0 & 0.0 & -0.5 & 0.0 & -9.2 & 9.9 & -5.5 \\
GER & 0.0 & 0.0 & -1.1 & 0.0 & -0.5 & 0.0 & -9.3 & 10.0 & -5.5 \\
UK & 0.0 & 0.0 & -1.1 & 0.0 & -0.5 & 0.0 & -10.4 & 11.1 & -5.5 \\
GRC & 0.0 & 0.1 & -1.9 & 0.1 & -1.0 & 0.0 & -16.6 & 17.5 & -6.0 \\
IRL & 0.0 & 0.0 & -1.1 & 0.0 & -0.5 & 0.0 & -16.3 & 17.0 & -5.5 \\
ITA & 0.0 & 0.1 & -1.3 & 0.1 & -0.6 & 0.0 & -9.2 & 10.2 & -5.6 \\
NLD & 0.0 & 0.1 & -2.3 & 0.1 & -1.1 & 0.0 & -18.4 & 19.2 & -6.1 \\
PRT & 0.0 & 0.1 & -1.3 & 0.0 & -0.7 & 0.0 & -10.7 & 11.2 & -5.7 \\
ESP & 0.0 & 0.1 & -1.4 & 0.1 & -0.7 & 0.0 & -9.9 & 10.6 & -5.7 \\
SWE & 0.0 & 0.0 & -0.8 & 0.0 & -0.4 & 0.0 & -6.1 & 6.6 & -5.4 \\
CHE & 0.0 & 0.0 & -0.3 & 0.0 & -0.2 & 0.0 & -7.3 & 7.9 & -5.2 \\
EFT & 0.0 & 0.0 & -1.0 & 0.0 & -0.5 & 0.0 & -8.9 & 9.6 & -5.5 \\
REU & 0.0 & 0.1 & -1.4 & 0.1 & -0.7 & 0.1 & -6.1 & 7.0 & -5.7 \\
CZE & 0.0 & 0.1 & -1.2 & 0.1 & -0.6 & 0.0 & -6.2 & 6.8 & -5.6 \\
POL & 0.0 & 0.1 & -1.5 & 0.1 & -0.8 & 0.0 & -9.0 & 9.8 & -5.8 \\
HUN & 0.0 & 0.1 & -1.6 & 0.1 & -0.8 & 0.0 & -10.8 & 11.6 & -5.8 \\
RET & 0.0 & 0.1 & -1.4 & 0.1 & -0.7 & 0.1 & -5.4 & 6.2 & -5.7 \\
RUS & 0.0 & 0.1 & -2.7 & 0.1 & -1.3 & 0.1 & -12.9 & 14.5 & -6.3 \\
XSU & 0.0 & 0.1 & -1.2 & 0.1 & -0.6 & 0.1 & -3.7 & 4.5 & -5.6 \\
ROW & 0.0 & 0.1 & -1.6 & 0.1 & -0.8 & 0.0 & -8.9 & 9.6 & -5.8 \\
\hline
\end{tabular}


Table 8: Regional Aggregation

\begin{tabular}{|l|l|c|}
\hline Code & Description & Participant to EU-ETS \\
\hline NAF & North-American Free-Trade Area & \\
AUT & Austria & $\sqrt{ }$ \\
BEL & Belgium & $\sqrt{ }$ \\
DNK & Denmark & $\sqrt{ }$ \\
FIN & Finland & $\sqrt{ }$ \\
FRA & France & $\sqrt{ }$ \\
GER & Germany & $\sqrt{ }$ \\
UK & Great Britain & $\sqrt{ }$ \\
GRC & Greece & $\sqrt{ }$ \\
IRL & Ireland & $\sqrt{ }$ \\
ITA & Italy & $\sqrt{ }$ \\
NLD & Netherlands & $\sqrt{ }$ \\
PRT & Portugal & $\sqrt{ }$ \\
ESP & Spain & \\
SWE & Sweden & $\sqrt{ }$ \\
CHE & Switzerland & $\sqrt{ }$ \\
EFT & European Free-Trade Area \\
REU & Rest of EU & $\sqrt{ }$ \\
CZE & Czech Republic & $\sqrt{ }$ \\
POL & Poland & \\
HUN & Hungary & \\
RET & Rest of Eastern Europe & \\
RUS & Russian Feredation & \\
XSU & Rest of Former Soviet Union & \\
ROW & Rest of the World & \\
${ }^{a}$ USA, Canada, Mexico & \\
${ }^{b}$ Norway and Iceland & \\
${ }^{c}$ Cyprus, Estonia, Latvia, Lithuania, Luxembourg, Malta, Slovenia, Slovakia \\
\end{tabular}

Table 9: Sectoral Aggregation

\begin{tabular}{|l|l|l|}
\hline EU-ETS Covered Sectors & Combustion Sectors & Non-Covered Sectors \\
\hline Refined coal and petroleum & Coal Mining $^{a}$ & Transportation \\
Pulp and paper & Crude oil and gas mining $^{a}$ & Rest of Economy Aggregate \\
Electric power & Gas production and distribution & \\
Non-metallic mineral products & & \\
Iron and steel & Non-ferrous metals & \\
& Chemical, rubber and misc. plastics & \\
& Durable manufactures & \\
& Non-durable manufactures & \\
\hline
\end{tabular}

${ }^{d}$ Sector producing a fossil fuel whose use generates emissions of $\mathrm{CO}_{2}$ 